\title{
Los nuevos sujetos imperiales del valle de Copiapó: estilos Diaguita e Inca local en los pucos del período Tardío
}

\section{The new imperial subjects from Copiapó valley: Diaguita and Inca local styles on Late period pottery bowls}

\author{
Francisco Javier Garrido Escobar ${ }^{1}$
}

\begin{abstract}
Resumen
Durante la expansión imperial inca, fueron introducidas nuevas formas y estilos cerámicos en el valle de Copiapó. Más allá de la presencia de nuevas vasijas como aríbalos, aisanas y escudillas planas, las vasijas locales no restringidas de perfil simple o 'pucos' permanecen en el tiempo e incorporan en su decoración una mezcla de estilos diaguita-inca reinterpretados localmente.

Este artículo se basa en el análisis morfológico y estilístico de colecciones museológicas de pucos tardíos de la costa y valle de Copiapó, sin considerar aquellos tipos locales Copiapó negro sobre rojo. Las configuraciones estilísticas más abundantes en la muestra analizada son el patrón Zigzag, Doble zigzag, Rombos y Triángulos en Doble Reflexión Especular y Greca Inca, incluyendo variantes que reinterpretan localmente diseńos cuzqueños y diaguita. La creación de estos nuevos tipos es un posible reflejo del surgimiento de nuevas identidades sociales, en donde los actores sociales locales negociaron los referentes simbólicos de su cultura material durante una época de importantes cambios en lo político y social.
\end{abstract}

Palabras claves: Imperio inca, Copiapó, estilos cerámicos, Diaguita Inca.

\begin{abstract}
During the Inca imperial expansion, new kinds of pottery forms and styles appeared in Copiapó valley. Besides the presence of new pots such as aríbalos, aisanas, and shallow plates, local unrestricted and simple profile pots persisted. Furthermore, their designs incorporated a mix of locally re-interpreted Diaguita-Inca styles.

This paper is based on the morphological and stylistic analysis of pots from museum collections, which came from Copiapó coast and valley, excluding the Copiapó black-on-red style local pots. The most abundant stylistic patterns in the sample are the Zigzag, Double Zigzag, Diamonds in Double Mirror Reflection, and Greca Inca including all their variations, which are local interpretations of Cuzco and Diaguita designs. The creation of these new types suggests the rise of new social identities, where local actors negotiated the symbolic referents of their material culture during a time of important political and social changes.
\end{abstract}

Keywords: inca empire, Copiapó, pottery styles, Diaguita Inca.

Recibido: 5 diciembre 2016. Aceptado: 24 octubre 2017

1 Museo Nacional de Historia Natural, Santiago, CHILE. Email: francisco.garrido@mnhn.gob.cl 


\section{Introducción}

La expansión inca en el valle de Copiapó generó una serie de cambios sociales y políticos, los cuales también se expresaron en la cultura material de las poblaciones locales. Más allá de la introducción de nuevos tipos cerámicos con formas incaicas, este artículo trata de aquellas vasijas de formas locales, particularmente los pucos, que incorporaron nueva decoración de influencia diaguita e inca durante esta época. Se considera que esto responde a un proceso tanto de imposición como de agencia local en la redefinición de sus referentes identitarios e ideológicos.

La interpretación actual de la incorporación del valle de Copiapó al Imperio inca plantea que ésta habría acontecido a través de la intermediación de grupos diaguitas. Esto se basa en el hecho de que los estilos incaicos están en su mayoría combinados con aquellos diaguita (Cornely, 1956; Ampuero, 1978; Niemeyer et al., 1993; Castillo, 1998; González, 2000). Dado aquello, se ha postulado la existencia de una alianza entre el Imperio inca y ciertos segmentos de la sociedad diaguita con el fin de actuar como administradores de los nuevos territorios, sugiriendo así una conquista de sur a norte hasta incorporar el valle de Copiapó (Berenguer, 2009; Cornejo, 2001; González, 2013; Troncoso y Pavlovic, 2013; Uribe y Sánchez, 2016). Los cambios políticos y la llegada de nuevos grupos administrativos junto a sus estilos cerámicos indujeron cambios estilísticos en el repertorio alfarero local. Sin embargo, hasta ahora es poco conocido cómo dichos cambios se manifestaron en la producción de vasijas de morfologías no incaicas durante el período Tardío.

En tal sentido, es relevante destacar que la incorporación de los nuevos estilos decorativos de influencia diaguita e inca se manifiesta sobre una tradición alfarera de larga data, en donde las vasijas no restringidas conocidas como pucos tienen una presencia regional desde el período Medio (Garrido, 2011). Por lo anterior es que este trabajo busca interpretar los cambios alfareros acontecidos durante la época de dominación imperial, a través del estudio de formas cerámicas que expresan cómo las poblaciones locales negociaron nuevos contenidos ideológicos en su cultura material. Bajo dicha lógica podríamos esperar que una fuerte imposición incaica resultara en una baja variabilidad de diseños, con alta estandarización en su configuración iconográfica. Por el contrario, una alta diversidad de configuraciones decorativas expresadas como variantes locales de motivos de influencia cuzqueńa podría sugerir una interpretación iconográfica no monopolizada por el Estado, y quizás en función de las lógicas propias de las poblaciones locales de los nuevos territorios incorporados al imperio.

\section{La cerámica del período Tardío en Copiapó}

La cerámica del período Tardío en la región consiste tanto en tipos que provienen del Intermedio Tardío regional como lo son el Copiapó negro sobre rojo y el Punta Brava, además de la incorporación de nuevas variedades como el Diaguita III, y un grupo reducido de vasijas con categorías formales de vasijas propias del Tawantinsuyu. En general, las excavaciones en áreas nucleares del imperio han dado cuenta de la gran variabilidad morfológica de la cerámica inca, donde a modo de ejemplo, las investigaciones realizadas en el complejo real de Chinchero han reconocido hasta 28 tipos diferentes (D'Altroy, 2015). Sin embargo, la clasificación más utilizada hasta ahora es la de Meyers (1975), quien en sus excavaciones en Sacsahuamán identificó 14 formas básicas para la cerámica inca, organizadas en siete categorías de vasijas. Bray $(2003,2004,2009)$ ha retomado dicha clasificación, dando cuenta de que aquellas siete categorías también estarían presentes en las provincias, pero con una predominancia fundamental del aríbalo, debido al consumo de chicha como parte de prácticas de redistribución y comensalidad estatal. En contraste, para el caso de Chile el repertorio sería más reducido, principalmente de cuatro categorías morfológicas (Figura 1). Éstas consistirían en aríbalos, escudillas, ollas de pedestal y aisanas (Berenguer, 2009). Si bien otras categorías como keros y pakchas también se encuentran en el país, su representación sería muy baja en comparación con el resto.

Respecto a los estilos inca presentes en las provincias del sur del Collasuyo, la clasificación más utilizada es la de Calderari y Williams (1991), quienes definieron cuatro categorías principales: Inca cuzqueño procedente del área nuclear del imperio; Inca local, 


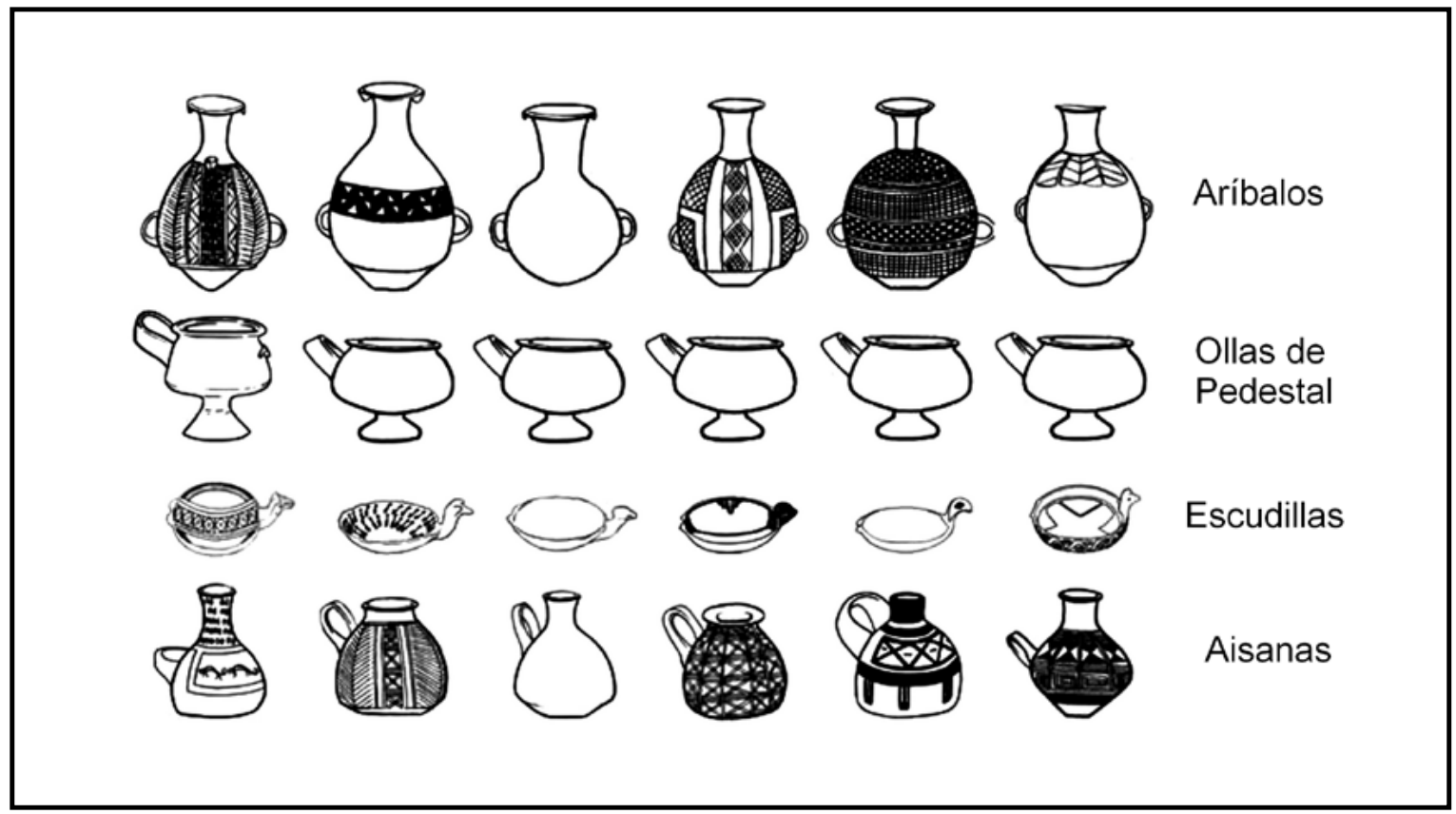

Figura 1: Variación de las categorías formales de la cerámica inca en Chile (modificado de Berenguer, 2009, p. 91).

considerando vasijas con forma y decoración inca de manufactura local; Inca mixto, que incluye piezas que fusionan estilos locales y cuzqueños; y alfarería de fase Inca, que refleja variaciones en formas locales y el surgimiento de nuevos estilos decorativos como producto de los cambios sociopolíticos acontecidos en el período Tardío. Esta clasificación ha sido utilizada por varios investigadores en el Norte Chico y la zona central de Chile (Cantarutti y Mera, 2001; Cantarutti y Mera, 2004; Correa et al., 2004; Sanhueza, 2001, entre otros), dando como resultado la constante identificación de una amplia proporción de tipos cerámicos de estilo inca local y mixto presentes en tal territorio. Tal situación sería similar para el valle de Copiapó (Castillo, 1998; Niemeyer, 1986), en donde la presencia de lo inca cuzqueño es muy baja y la mayor parte de la alfarería de la época sería de manufactura local.

Si bien existen algunas descripciones generales de la cerámica del período Tardío de la región de Atacama (Castillo, 1998; Iribarren, 1958; Niemeyer, 1986, 1993), aún carecemos de estudios detallados sobre las variedades decorativas locales con influencia incaica. Dada la relevancia del tema para la mejor comprensión de la incorporación de estas sociedades provinciales al imperio, es que este trabajo se centra en el estudio de colecciones museográficas con el fin de contribuir en tal objetivo. Para ello, se analizaron los pucos del período Tardío "Inca mixto", con decoración Diaguita III y de "fase Inca", que corresponden a categorías de vasija con gran abundancia en la época en esta zona.

\section{Material y muestra}

Para este estudio se analizaron 57 vasijas, en su mayoría completas, incluyendo algunas fragmentadas en las cuales fuese posible reconocer la totalidad de su configuración decorativa y medidas formales. Todas las vasijas corresponden a pucos Tardíos de sitios de la costa e interior del valle de Copiapó. En varios casos solo se pudo constatar una localización genérica como la ciudad de Copiapó, Caldera o la comuna de Tierra Amarilla, por lo cual se ha optado por una división en dos categorías que corresponden a la costa e interior del valle de Copiapó. Sobre información de sitios, solo tenemos registros fidedignos de vasijas de Iglesia Colorada en contextos de funebria, de donde provienen unos 13 ejemplares. Piezas del 
Tabla 1. Procedencia de la muestra de estudio.

\begin{tabular}{|l|c|c|c|}
\hline Museos de Procedencia & Costa & Valle de Copiapó & Total \\
\hline Museo Nacional de Historia Natural & 6 & 8 & $\mathbf{1 4}$ \\
\hline Museo de Historia Natural de Valparaíso & 8 & 0 & $\mathbf{8}$ \\
\hline Museo Regional de Atacama & 1 & 34 & $\mathbf{3 5}$ \\
\hline Total & 14 & 42 & 57 \\
\hline
\end{tabular}

valle del Huasco o del despoblado de Atacama no han sido consideradas para este estudio, con el fin de enfocarnos en los procesos sociales de las comunidades del valle de Copiapó. Las colecciones de la muestra de estudio proceden del Museo Nacional de Historia Natural, Museo de Historia Natural de Valparaíso y Museo Regional de Atacama, tal como es posible apreciar en la Tabla 1 .

Esta muestra constituye la totalidad de los pucos tardíos del valle que albergan los mencionados museos. En ella no se incluyen los pucos Copiapó negro sobre rojo, los Copiapó negro sobre rojo y crema, ni vasijas Punta Brava, los cuales ya han sido analizados en otras oportunidades (Garrido, 2007, 2011, 2014). Del mismo modo, tampoco se incluyen escudillas incaicas ni otras morfologías que no sean los referidos pucos del período Tardío.

Para todas las piezas se analizaron sus medidas de espesor, alto, diámetro, además de efectuar el registro completo de su decoración interior y exterior. Sobre este último tema se consideró el estudio de sus configuraciones de diseño, además de la identificación de motivos individuales. Para esto se ha considerado el comprehensivo trabajo de clasificación de González (2013), el cual incluye y expande sus clasificaciones previas (González, 1995, 2004), sobre la base de los estudios iniciales de Cornejo (1989). En tal sentido, este trabajo busca identificar tanto las similitudes con estilos diaguita e inca, así como también las variantes locales creadas durante la época en el valle de Copiapó.

\section{Morfología de la cerámica Copiapó-Inca- Diaguita}

Como ha sido señalado anteriormente, este trabajo se enfoca en los pucos con influencia DiaguitaInca en el valle de Copiapó. El concepto de puco ha sido utilizado extensamente en la literatura regional y para los efectos de este trabajo se considerará al 'plato campanuliforme' como incluido dentro de la misma categoría. Esta categoría formal puede ser definida según los parámetros propuestos por Rice (1987, p. 216), en función de la relación entre alto máximo y diámetro de la vasija. De acuerdo a ello, puco correspondería a una vasija no restringida, en donde el alto máximo presenta una relación de entre $1 / 5$ a $1 / 2$ con respecto a su diámetro. Una vasija con una relación menor a un $1 / 5$ podría ser definida como escudilla o plato de paredes bajas, una morfología común dentro del repertorio incaico.

Al igual que los pucos Copiapó negro sobre rojo (Garrido, 2011), el resto de aquellos presentes en el valle de Copiapó durante el período Tardío poseen dos formas de perfil principales: 1) elipsoide vertical, conocidos comúnmente como "acampanados", y 2) hemisférico sin restricción. En ambos casos sus bordes pueden ser rectos o bien ligeramente evertidos. En cuando a sus bases, éstas pueden ser planas, cóncavas o semihundidas. En el caso de los pucos de paredes acampanadas, sus bases suelen ser planas y sin definición clara en relación al resto del cuerpo. Si bien las formas acampanadas se popularizan 

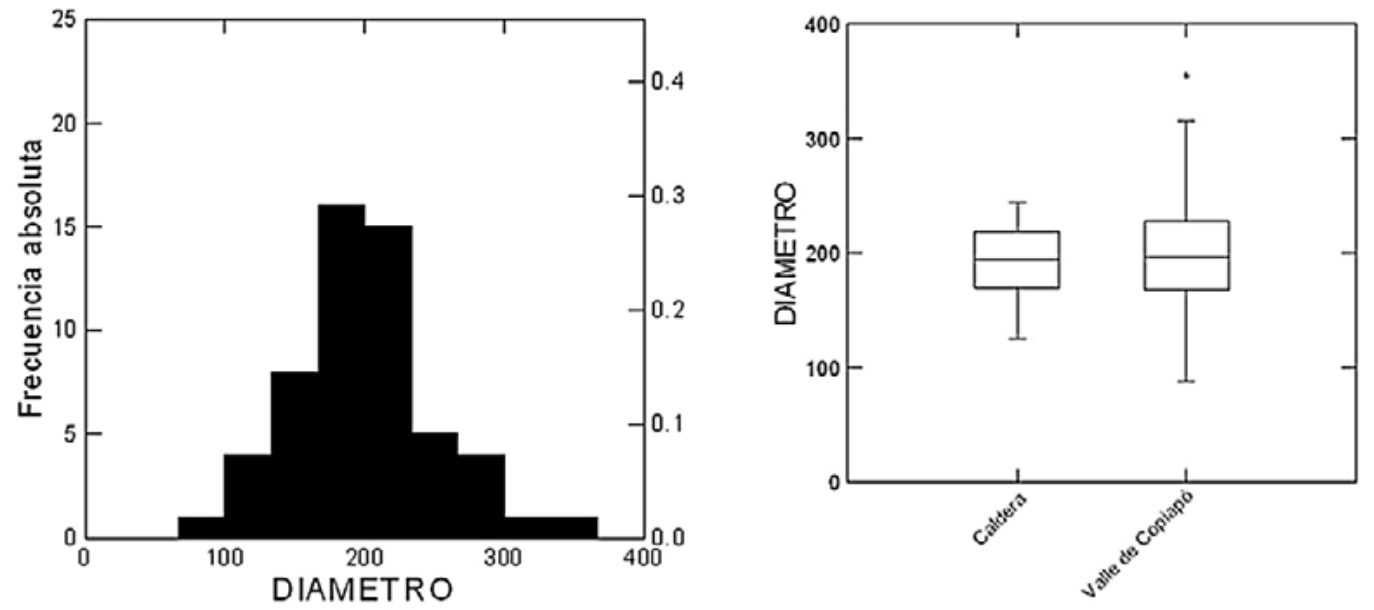

Figura 2. Histograma y diagrama de caja que muestra la distribución de medidas de diámetro en la muestra de estudio.

en la cerámica diaguita solamente hacia el Tardío (Ampuero, 1989; Cornely, 1956; González, 1995, 2013), esta morfología ya está plenamente presente desde el período Medio en el valle de Copiapó, siendo representada a través de los estilos Ánimas y posteriormente Copiapó negro sobre rojo (Castillo, 1998; Garrido, 2007, 2011).

\section{Dimensiones de diámetro, espesor y alto}

Las medidas de diámetro máximo de la muestra se distribuyen de modo normal con un valor de 198,6 $\mathrm{mm}$ (histograma Figura 2). Cuando segregamos las vasijas por localidad, vemos en el diagrama de caja de la misma Figura 2, que las vasijas del valle de Copiapó poseen una distribución mucho más heterogénea de valores que en la costa, yendo desde cerca de $100 \mathrm{~mm}$ hasta más allá de $300 \mathrm{~mm}$. La presencia de vasijas de mayor tamańo en el interior del valle podría deberse a la existencia de una mayor diversidad de centros productores de alfarería y/o a una mayor cantidad de usuarios que favorecería el uso de recipientes con mayor capacidad de volumen de alimento.

En relación a las medidas de espesor, el promedio de valores en la muestra es de $4,45 \mathrm{~mm}$. El histograma de la izquierda de la Figura 3 muestra una distribución normal, pero con un cierto incremento en los valores más altos que ronda los $7 \mathrm{~mm}$, correspondiendo éstos a vasijas de mayor tamaño. No hay una diferencia significativa entre el valle y la costa, pero en el primero hay una mayor dispersión de valores extremos, en donde su promedio compensa las diferencias. En cuanto al alto de cuerpo, el histograma de la derecha de la Figura 3 muestra una distribución ligeramente bimodal, con un leve aumento de frecuencia en los valores más altos. Por su parte, en el gráfico inferior de la Figura 3 vemos que la relación entre alto de cuerpo y diámetro muestra una correlación positiva relativamente poderosa, con un valor $\mathrm{r}$ de 0.828 y un $\mathrm{r} 2$ de 0.6858 . Esto significa que a mayor diámetro de la vasija, mayor será su alto de cuerpo de modo directamente proporcional. En cuanto a la localidad de procedencia, las vasijas de la costa presentan un promedio de $82.1 \mathrm{~mm}$ de alto de cuerpo, mientras que las del interior del valle de Copiapó tienen un promedio de $88.7 \mathrm{~mm}$, lo cual se relaciona con lo anteriormente expuesto sobre el mayor tamaño relativo de las vasijas pertenecientes a esta última zona geográfica. 

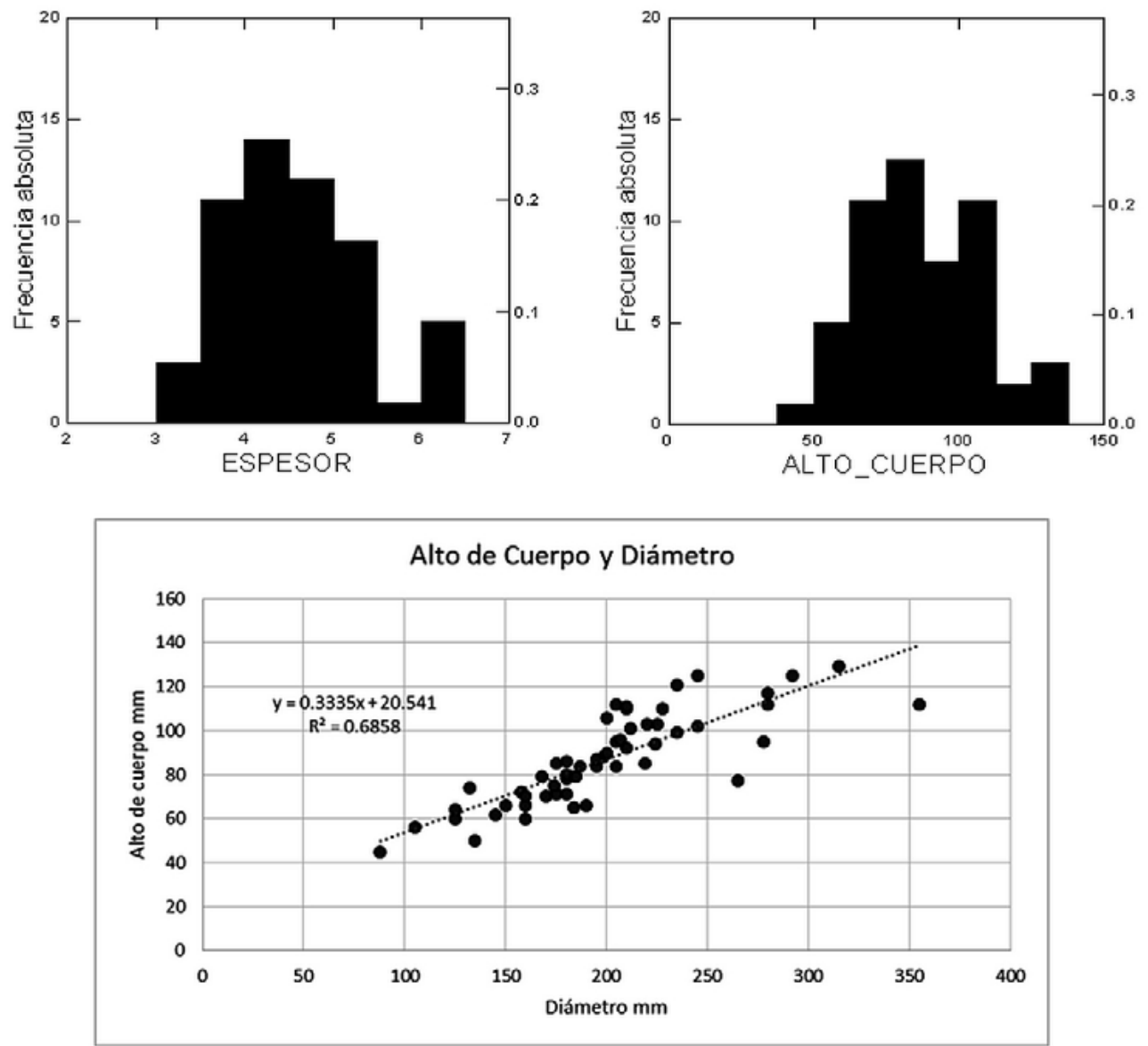

Figura 3. Arriba, histogramas que muestran la frecuencia de las medidas de espesor y alto de cuerpo en la muestra de estudio. Abajo, gráfico de dispersión con medidas de diámetro y alto de cuerpo.

\section{Campos de diseño}

Los campos de diseño, referidos en este caso a la configuración espacial de la superficie en donde se expresa la decoración, se presentan en los pucos de la muestra bajo la modalidad de campos continuos y campos discretos (incluyendo diseños finitos). Éstos se aprecian en la Figura 4 y se describen a continuación.

\section{Campos discretos}

Se refiere a la disposición de la decoración en dos o más campos claramente delimitados. Generalmente esto se da por medio de líneas negras gruesas que subdividen la superficie decorada. Este tipo de cam- po de diseño solo se aprecia en la superficie exterior de los pucos analizados, alcanzando al 50,9\% de la muestra. Si bien en la mayoría de los casos hay dos campos, los pucos decorados con un rostro zoomorfo tienen tres campos discretos delimitados.

Una modalidad particular de campos discretos se refiere a la presencia de diseńos finitos, los cuales son acotados y no se enmarcan en grandes rectángulos con líneas negras. La principal configuración de ellos se da a modo de cuatripartición en la superficie interior de las vasijas con un $76,5 \%$ de los casos, versus un $11,5 \%$ donde esta configuración se presenta en la superficie exterior. 


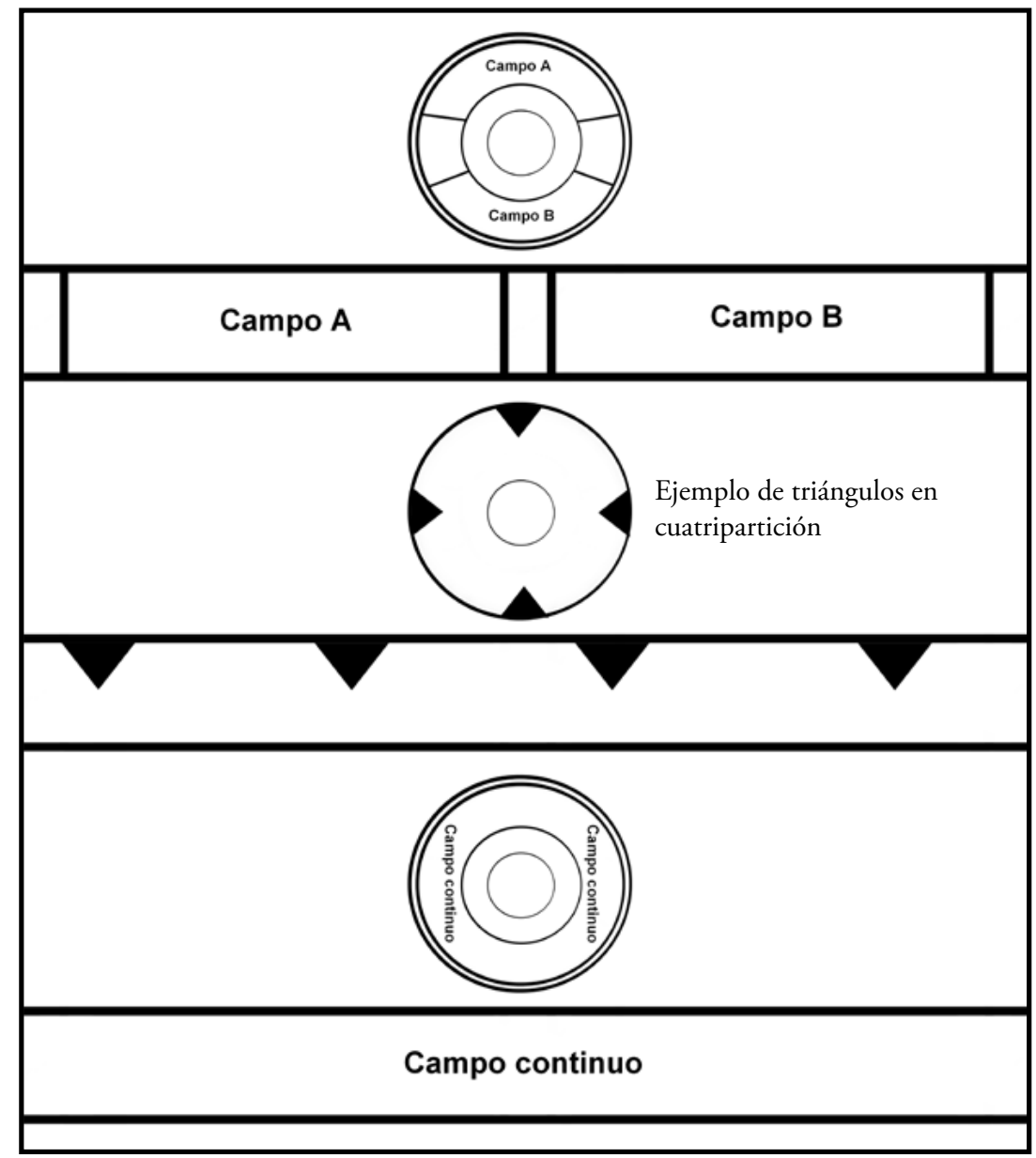

Figura 4. Vista de la configuración de campos discretos, diseños finitos y campo continuo en planta y a modo de banda.

\section{Campos continuos}

Esta configuración se refiere a la presencia de una banda de decoración continua por la superficie exterior o interior de la vasija, sobre la cual puede estar expresado un diseńo unidireccional o bidimensional. Generalmente la banda se delimita por líneas negras en sus extremos superiores e inferiores y representa un $33,3 \%$ del total de la muestra de estudio.

\section{Configuraciones de diseño y sus variantes en la muestra de estudio}

En esta sección pasaremos a detallar los principales diseńos y motivos decorativos presentes en los pucos Tardíos de la costa y valle de Copiapó. Para esta clasificación se seguirá preferentemente el criterio de González (2013), con el fin de establecer una base de comparación con aquello ya conocido sobre la decoración diaguita-inca. Las clasificaciones decorativas previas han seguido un criterio mixto que involucra tanto principios de simetría (por ejemplo, Doble reflexión especular, Traslación, etc.) como también, patrones de diseño basados en unidades geométricas repetitivas y específicas (por ejemplo, patrón Zigzag, Ondas, Cadenas, etc.). Asumiendo los posibles inconvenientes de una clasificación mixta de este tipo, es que todas aquellas categorías decorativas serán consideradas como "configuraciones de diseño", entendiendo que representan manifestaciones visuales fácilmente discernibles, identificables y repetitivas. De este modo, es posible identificar las diferencias y similitudes con la alfarería Diaguita Inca de la zona del 
Elqui al sur, con el fin de comprender la especificidad de las manifestaciones visuales del valle de Copiapó.

Basado en lo anterior, las configuraciones de diseño identificadas en la muestra de estudio se señalan a continuación.

\section{Patrón Zigzag}

Este patrón es uno de los predominantes en la muestra de estudio. Fue definido por Cornejo (1989) como un diseño unidireccional que reproduce un elemento por medio de una serie de reflexiones laterales en 45 grados. En la muestra de estudio se han identificado tres grandes categorías, cuya gran mayoría de variantes corresponde a expresiones locales de la zona de Copiapó. Las categorías principales son: 1) triángulos equiláteros y volutas cuadradas, 2) triángulos rectángulos con volutas cuadradas, y 3) triángulos equiláteros con otros diseños. Sus variantes detectadas en este estudio se aprecian en la Figura 5 y se describen a continuación.

\section{Patrón Zigzag de triángulos equiláteros y volutas cuadradas}

Este patrón se compone de un par de volutas cuadradas insertas en la base de un triángulo equilátero negro. Los triángulos se reflejan y desplazan horizontalmente. Este patrón presenta cierta similitud con el patrón Diaguita Zigzag J (González, 2013, p. 87), pero su configuración y subvariantes son específicas del valle de Copiapó. En la muestra de estudio encontramos siete ejemplares con este patrón.

Tabla 2. Variantes Patrón 5.1.1

\begin{tabular}{|l|c|c|}
\hline Variante & $\mathbf{N}^{\circ}$ de ejemplares & $\begin{array}{c}\text { Campos de } \\
\text { diseńo }\end{array}$ \\
\hline 5.1 .1 .1 & 4 & $\begin{array}{l}\text { Unidades } \\
\text { discretas }\end{array}$ \\
\hline 5.1 .1 .2 & 1 & $\begin{array}{l}\text { Unidades } \\
\text { discretas }\end{array}$ \\
\hline 5.1 .1 .3 & 1 & $\begin{array}{l}\text { Unidades } \\
\text { discretas }\end{array}$ \\
\hline 5.1 .1 .4 & 1 & Continuo \\
\hline
\end{tabular}

Patrón Zigzag triángulos rectángulos con volutas cuadradas

Este patrón presenta dos triángulos rectángulos opuestos por su hipotenusa. En el ángulo opuesto a la hipotenusa se genera una voluta cuadrada. Estos triángulos opuestos se desplazan de modo horizontal y en varios casos están separados por líneas verticales de color rojo y negro. En su mayor parte corresponde a variantes locales del valle de Copiapó con cierta lejana semejanza al patrón Zigzag Diaguita. La muestra de estudio posee ocho ejemplares pertenecientes a este patrón, las cuales se aprecian en la Tabla 3.

Tabla 3. Variantes Patrón 5.1.2

\begin{tabular}{|c|c|c|}
\hline Variante & $\begin{array}{c}\mathrm{N}^{\circ} \mathrm{de} \\
\text { ejemplares }\end{array}$ & $\begin{array}{l}\text { Campos de } \\
\text { diseño }\end{array}$ \\
\hline 5.1.2.1 & 1 & Continuo \\
\hline $\begin{array}{l}\text { 5.1.2.2 } \\
\text { Patrón Zigzag M2 } \\
\text { (González, 2013, } \\
\text { 89) }\end{array}$ & 2 & Continuo \\
\hline $\begin{array}{l}\text { 5.1.2.3 } \\
\text { Patrón Zigzag C4 } \\
\text { (González, 2013, } \\
84 \text { ) }\end{array}$ & 1 & Continuo \\
\hline 5.1.2.4 & 1 & $\begin{array}{l}\text { Unidades } \\
\text { discretas }\end{array}$ \\
\hline $\begin{array}{l}\text { 5.1.2.5 } \\
\text { Patrón Zigzag C3 } \\
\text { (González, 2013, } \\
84 \text { ) }\end{array}$ & 1 & $\begin{array}{l}\text { Unidades } \\
\text { discretas }\end{array}$ \\
\hline 5.1.2.6 & 1 & $\begin{array}{l}\text { Continuo (franja } \\
\text { interior) }\end{array}$ \\
\hline 5.1.2.7 & 1 & $\begin{array}{l}\text { Unidades } \\
\text { discretas }\end{array}$ \\
\hline $\begin{array}{l}\text { 5.1.2.8 } \\
\text { Patrón Zigzag C5 } \\
\text { (González, 2013, } \\
85 \text { ) }\end{array}$ & 1 & $\begin{array}{l}\text { Unidades } \\
\text { discretas }\end{array}$ \\
\hline
\end{tabular}


Patrón Zigzag

5.1.1Patrón Zigzag de triángulos equiláteros y volutas cuadradas

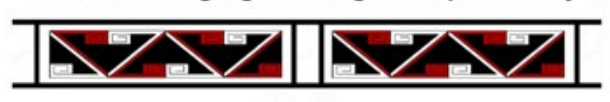

5.1.1.1

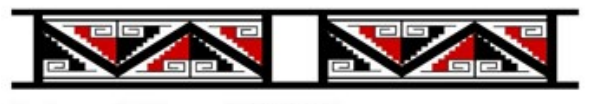

5.1.1.3

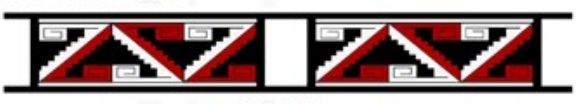

5.1 .1 .2

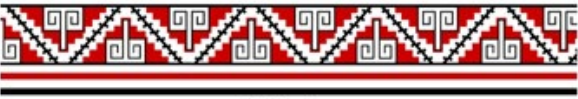

5.1.1.4

5.1.2 Patrón Zigzag triángulos rectángulos con volutas cuadradas

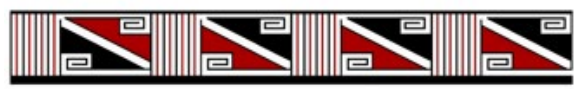

5.1.2.1

\begin{tabular}{|c|c|c|}
\hline 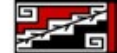 & 回少 & 四肃 \\
\hline
\end{tabular}

5.1.2.3

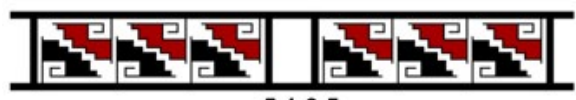

5.1 .2 .5

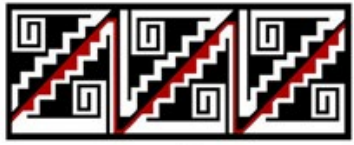

5.1.2.7

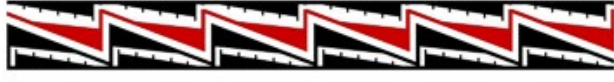

5.1 .2 .2

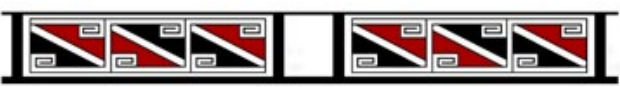

5.1.2.4

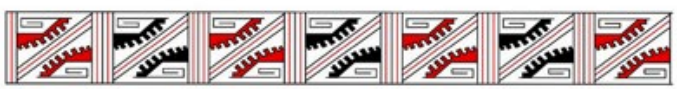

5.1.2.6

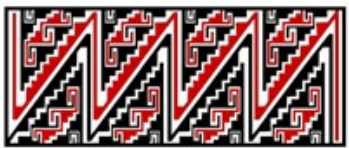

5.1.2.8

5.1.3 Patrón Zigzag de triángulos isósceles opuestos

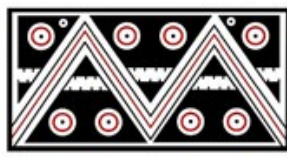

5.1.3.1

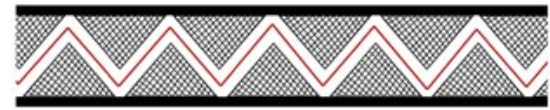

5.1.3.2

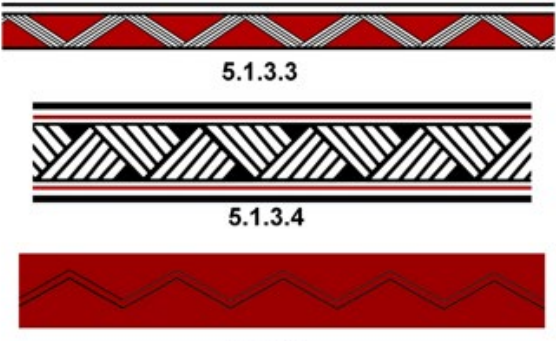

5.1.3.5

Figura 5. Patrón Zigzag y sus variantes en la muestra de estudio. 


\section{Patrón Doble Zigzag}

5.2.1 Doble Zigzag con volutas cuadradas

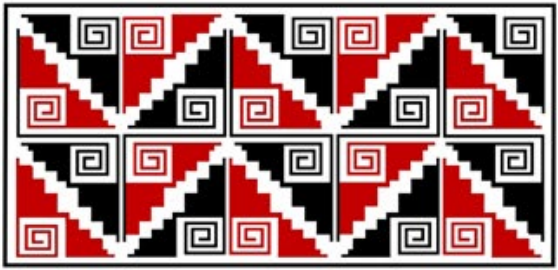

5.2.1.1

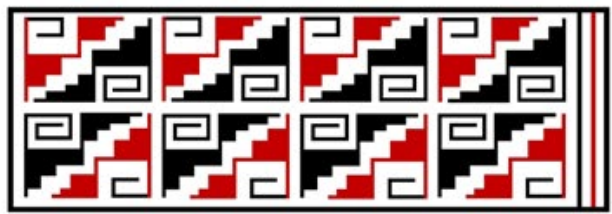

5.2.1.2a
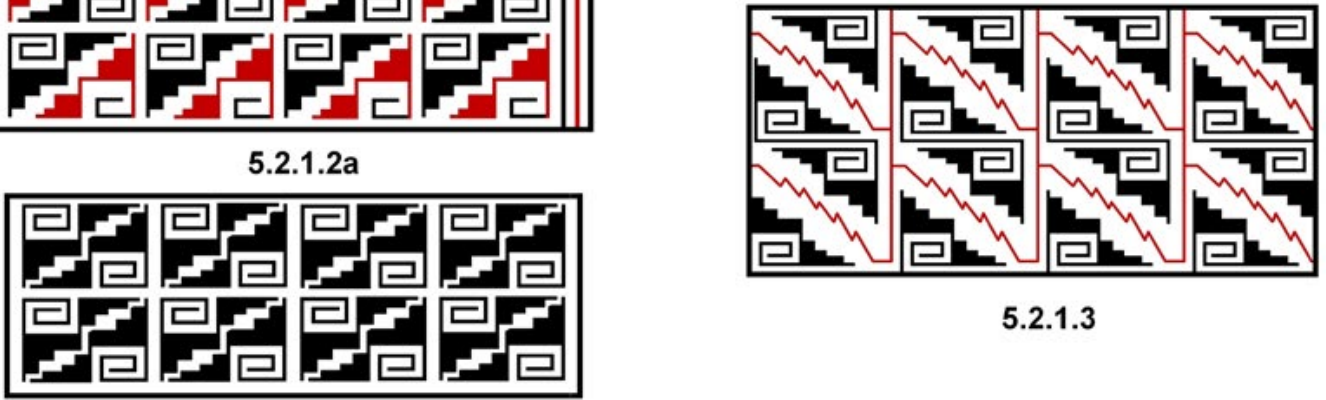

5.2.1.3

5.2.1.2b

5.2.2 Patrón Doble Zigzag con triángulos isósceles y círculos concéntricos

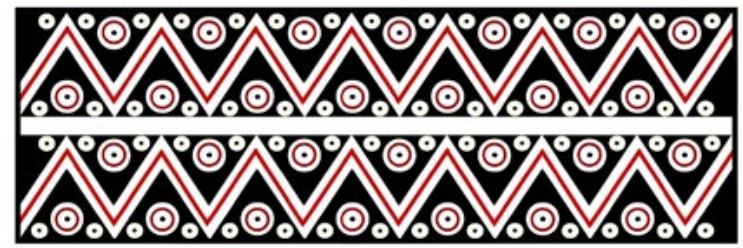

5.2.3 Patrón Doble Zigzag con cuadrado negro y apéndice vertical

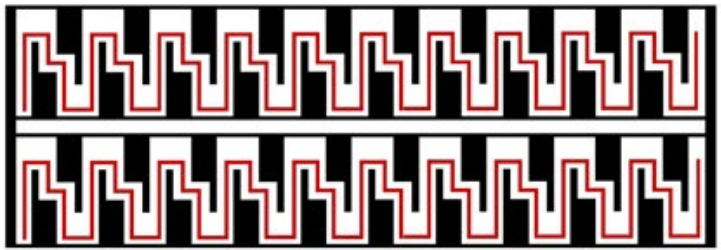

Figura 6. Patrón Doble Zigzag y sus variantes presentes en la muestra de estudio. 
Patrón Zigzag de triángulos isósceles opuestos

Este patrón Zigzag se define por la presencia de triángulos opuestos verticalmente de modo desplazado. Entre ellos, una o varias líneas paralelas zigzagueantes marcan su separación. La muestra de estudio posee seis ejemplares pertenecientes a esta categoría, las cuales se aprecian en la Tabla 4.

Tabla 4. Variantes Patrón 5.1.3

\begin{tabular}{|l|c|c|}
\hline \multicolumn{1}{|c|}{ Variante } & \multicolumn{1}{c|}{$\begin{array}{c}\mathbf{N}^{\circ} \text { de } \\
\text { ejemplares }\end{array}$} & $\begin{array}{c}\text { Campos de } \\
\text { diseńo }\end{array}$ \\
\hline $\begin{array}{l}\text { 5.1.3.1 } \\
\text { Patrón Zigzag L2 } \\
\text { (González 2013:88) }\end{array}$ & 3 & $\begin{array}{c}\text { Unidades } \\
\text { discretas }\end{array}$ \\
\hline $\begin{array}{l}\text { 5.1.3.2 } \\
\text { Patrón Zigzag } \\
\text { Cuzqueńo A }\end{array}$ & 1 & Continuo \\
\hline $\begin{array}{l}\text { González 2013:239) } \\
\text { Patrón Zigzag B2 } \\
\text { (González 2013:82) }\end{array}$ & 1 & Continuo \\
\hline $\begin{array}{l}5.1 .3 .4 \\
5.1 .3 .5\end{array}$ & 1 & $\begin{array}{c}\text { Continuo } \\
\text { (franja interior) }\end{array}$ \\
\hline
\end{tabular}

\section{Patrón Doble Zigzag}

Este patrón fue definido originalmente por Cornejo (1989) y constituye un diseño bidimensional. En general, consiste en la adición de un segundo eje superpuesto verticalmente sobre un diseño de patrón Zigzag simple. Sus variantes detectadas en este estudio se aprecian en la Figura 6 y se describen a continuación.

\section{Patrón Doble Zigzag con volutas cuadradas}

Es un patrón similar al Zigzag con volutas cuadradas, pero esta vez constituyendo un diseño bidimensional. La muestra de estudio posee cinco ejemplares pertenecientes a esta categoría. Sus variantes se describen a continuación en la Tabla 5.
Tabla 5. Variantes Patrón 5.2.1

\begin{tabular}{|l|c|c|}
\hline \multicolumn{1}{|c|}{ Variante } & \multicolumn{1}{|c|}{$\begin{array}{c}\mathbf{N}^{\circ} \text { de } \\
\text { ejemplares }\end{array}$} & $\begin{array}{c}\text { Campos de } \\
\text { diseńo }\end{array}$ \\
\hline 5.2 .1 .1 & 1 & $\begin{array}{l}\text { Unidades } \\
\text { discretas }\end{array}$ \\
\hline $\begin{array}{l}\text { 5.2.1.2 } \\
\text { Patrón Doble Zigzag } \\
\text { D2-1 (González, 2013, } \\
\text { 99) o bien Doble Zigzag } \\
\text { G (González, 2013, 261) }\end{array}$ & 3 & $\begin{array}{l}\text { Unidades } \\
\text { discretas }\end{array}$ \\
\hline $\begin{array}{l}\text { 5.2.1.3 } \\
\text { Patrón Doble Zigzag D } \\
\text { (González 2013:98-99) }\end{array}$ & 1 & Continuo \\
\hline
\end{tabular}

\section{Patrón Doble Zigzag con triángulos isósceles y círculos concéntricos}

Ésta es una variante formada por dos ejes superpuestos de triángulos negros opuestos, separados por una línea roja zigzagueante. Cada triángulo posee tres círculos concéntricos, uno de los cuales es de mayor tamaño y se ubica en su centro. Este patrón se manifiesta en un diseño con campos discretos delimitados. La muestra de estudio posee un ejemplar perteneciente a esta categoría.

\section{Patrón Doble Zigzag con cuadrado negro y apéndice vertical, delimitado por línea roja escalonada}

Este patrón es idéntico al Doble Zigzag K (González, 2013, p. 103), el que se manifiesta como un diseño en campos discretos delimitado por líneas negras. La muestra de estudio posee un ejemplar perteneciente a esta categoría.

\section{La Greca Inca}

Uno de los patrones de diseño principales que se reconoce en pucos de perfil acampanado corresponde a una onda cuadrada que se desplaza a través de toda la superficie de la pieza por el exterior, generando entre dos y cinco crestas. Dicha onda cuadrada presenta un interior ajedrezado, el cual en su forma simple alterna colores blanco y negro, incorporando a veces el color rojo. Las líneas que demarcan el motivo son siempre de color negro. A su vez, cada segmento posee tres o cuatro divisiones ajedrezadas en su interior. 
De los pucos que presentan este diseño por su superficie exterior, solo hay un caso en donde también éste está presente al interior. En general, estos pucos muestran en su superficie interior motivos finitos delimitados en franjas verticales o triángulos, en su mayoría distribuidos a modo de cuatripartición. González (2013) describe un patrón no figurativo muy similar, denominado "Patrón Greca Inca B" (González, 2013, p. 209). Este patrón habría sido encontrado principalmente en el valle de Elqui y en menor proporción más al sur. En el caso de las variantes del patrón Greca Inca A, C, y D de González, éstas no estarían presentes en los patrones decorativos Copiapó-Inca.

El patrón Greca Inca fue definido inicialmente por Fernández Baca en 1971. El autor describe que este motivo "se destaca del fondo de la faja al haber sido trazadas sobre ésta rayas negras o de color granate en posición vertical alternativamente dispuestas en direcciones opuestas, guardando distancias uniformes entre sí mismas y el borde de dicha faja de color marfil o anaranjado en gamas diversas" (Fernández Baca, 1971, p. 50). En cuanto a la decoración que forma el relleno interior de la greca, las variaciones decorativas de este motivo (Fernández Baca, 1971, pp. 233-242) muestran colores sólidos o líneas negras paralelas, pero no la presencia de un diseńo ajedrezado en su interior. Por otra parte, el patrón descrito se presenta en aríbalos acompañado de otros motivos en traslación, dispuestas como franjas paralelas en el cuello. En el caso de ocupar el cuerpo del aríbalo, éste no ocupa la circunferencia total de la vasija.

\section{Variantes de la Greca Inca en Copiapó}

En Copiapó, este patrón de diseño muestra una variación fundamental con sus símiles cuzqueños, en cuanto a que lo único que conserva es su aspecto de onda cuadrada, difiriendo en su configuración decorativa y relleno interior. En los pucos acampanados puede ocupar prácticamente la totalidad del espacio del cuerpo al exterior de la vasija, repitiendo su configuración básica entre dos y cinco veces. En su interior presenta una estructura ajedrezada con tres subdivisiones interiores, aunque existen ejemplos con cuatro. Solo hay un caso en donde este diseño también se expresa en el interior del puco. La muestra de estudio posee seis ejemplares perte-

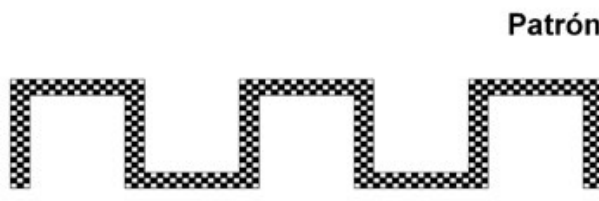

5.3.1.1

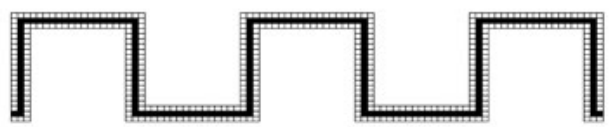

5.3.1.3a

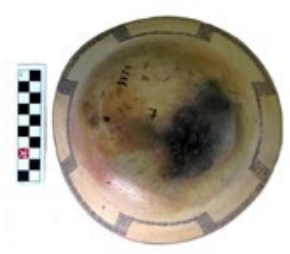

Patrón Greca Inca

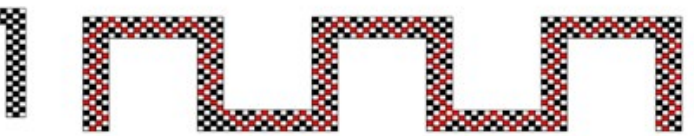

5.3.1.2

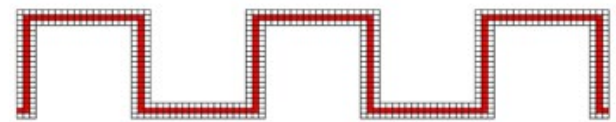

5.3.1.3b
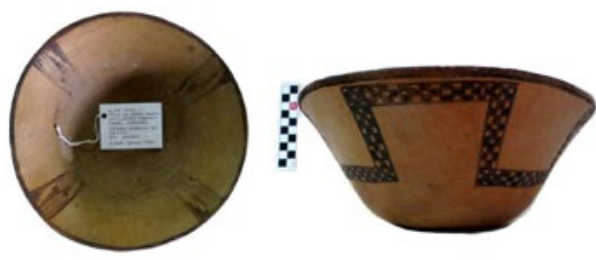

Figura 7. Patrón Greca Inca y sus variedades en la muestra de estudio, junto a una vasija de ejemplo. 
necientes a esta categoría. Las subvariedades de este patrón se muestran en la Figura 7 y se describen a continuación.

\section{Ajedrezado negro y blanco}

Presenta un patrón ajedrezado continuo en tonalidad blanco y negro. La muestra de estudio posee dos ejemplares con esta variante.

\section{Ajedrezado en rojo, negro y blanco}

Esta variante posee una estructura interna de cuatro segmentos cuadriculados en su interior. El color rojo se desplaza siguiendo un movimiento en zigzag a lo largo de todo el continuo del diseño. La muestra de estudio posee un ejemplar con esta variante.

Cuadriculado con borde negro y línea interior que sigue el contorno del diseño

Existen dos subvariantes cuya línea interior puede ser negra o roja. Al igual que el primer patrón descrito, poseen tres divisiones interiores en su sección. La subvariante B es la más similar al patrón Greca
Inca B de González (2013, p. 209). La muestra de estudio posee dos ejemplares con estas variantes.

\section{Patrón Cadenas}

El patrón Cadenas fue originalmente definido por Cornejo (1989) como aquél en donde un solo elemento se reproduce por medio de dos líneas de rotación a través de toda la superficie de la banda. La muestra de estudio posee tres ejemplares pertenecientes a dicho patrón. Éste tiene una baja representación en la muestra de estudio y presenta solo dos categorías. Sus variantes se aprecian en la Figura 8 y se describen a continuación.

\section{Rectángulo unido a un gancho}

Ésta es una variante del patrón Cadenas D, de González (2013, p. 137), en la cual los pares rotados de rectángulos con gancho se separan entre sí por líneas verticales negras y rojas. Este motivo forma una franja lineal sin repetición vertical para constituir un diseño bidimensional por el interior de la vasija. La muestra de estudio posee un ejemplar perteneciente a esta categoría.

\section{Patrón Cadenas}

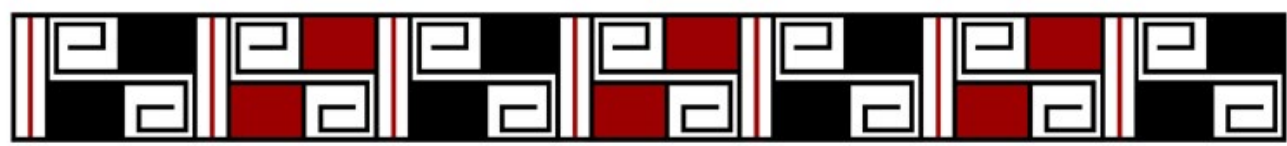

5.4.1 Rectángulo unido a un gancho

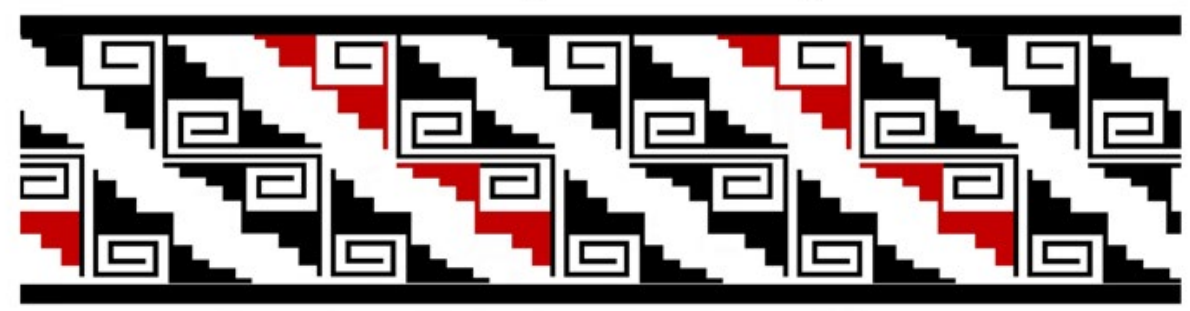

5.4.2 Escalerado con apéndice que termina en un gancho

Figura 8. Patrón Cadenas y sus variedades detectadas en la muestra de estudio. 
Escalerado con apéndice que termina en un gancho

Es una variante del patrón Cadenas C2 definido por González (2013, p. 133), en donde las unidades mínimas rotan entre sí con colores opuestos en sus escalonados. Este patrón se manifiesta en un diseño de banda continua a lo largo de la superficie exterior de la vasija. La muestra de estudio posee dos ejemplares pertenecientes a esta categoría.

\section{Patrón de Rombos y Triángulos en Doble Reflexión Especular}

Estas configuraciones corresponden a diseños bidireccionales cuya unidad mínima se refleja primero vertical y luego horizontalmente formando un diseńo cuatripartito. Su origen en la cerámica diaguita es atribuido por Gónzalez (2013) a la influencia incaica en sus estilos decorativos. Sus variantes detectadas en este estudio se aprecian en la Figura 9 y se describen a continuación.

\section{Rombos escalerados}

Corresponde de modo idéntico al patrón Doble Reflexión Especular D, de González (2013, p. 281).
Éste se compone de una greca escalonada negra inserta en un triángulo de color rojo, acompañada de otra en reflexión desplazada inserta en un triángulo de color blanco. La muestra de estudio posee dos ejemplares pertenecientes a esta categoría.

\section{Cuatro triángulos enfrentados por el vértice}

Patrón que presenta cuatro triángulos negros con círculos interiores opuestos por el vértice y formando un patrón en X. Sus variantes se aprecian en la Tabla 6.

Tabla 6. Variantes Patrón 5.5.2

\begin{tabular}{|c|c|c|}
\hline Variante & $\mathrm{N}^{\circ}$ de ejemplares & $\begin{array}{c}\text { Campos de } \\
\text { diseño }\end{array}$ \\
\hline $\begin{array}{l}5.5 .2 .1 \\
\text { Patrón Doble Reflexión } \\
\text { Especular F (González, } \\
\text { 2013, p. 282) }\end{array}$ & 4 & $\begin{array}{l}\text { Unidades } \\
\text { discretas }\end{array}$ \\
\hline 5.5 .2 .2 & 1 & $\begin{array}{l}\text { Unidades } \\
\text { discretas }\end{array}$ \\
\hline $\begin{array}{l}5.5 .2 .3 \\
\text { Patrón Doble Reflexión } \\
\text { Especular G (González, } \\
\text { 2013, p. 282) }\end{array}$ & 1 & $\begin{array}{l}\text { Unidades } \\
\text { discretas }\end{array}$ \\
\hline
\end{tabular}

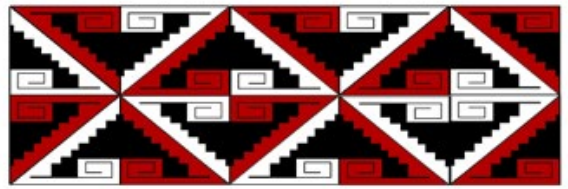

5.5.2 Cuatro triángulos enfrentados por el vértice

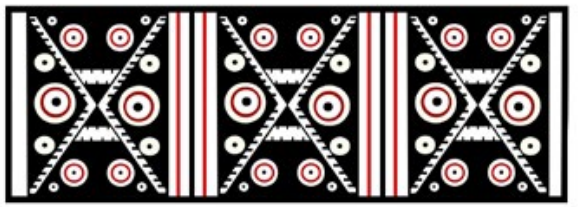

5.5.2.1

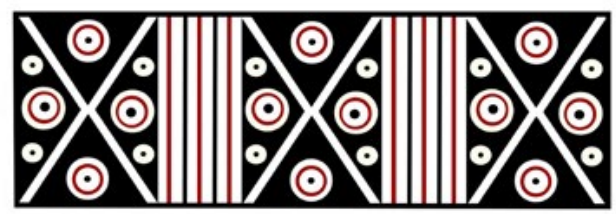

5.5.2.2

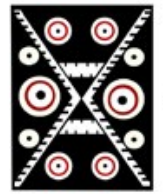

5.5.2.3

Figura 9. Patrón Rombos y Triángulos en Doble Reflexión Especular y sus variedades detectadas en la muestra de estudio. 


\section{Patrón Ondas}

El patrón Ondas fue definido originalmente por Cornejo (1989) y constituye un diseño bidimensional cuyas unidades mínimas tienen apéndices que se entrelazan y trasladan como un todo. Es un patrón de baja presencia en la muestra analizada, del cual se presentan dos variantes que no son exclusivas de la región. Sus variantes se aprecian en la Figura 10 y se describen a continuación.

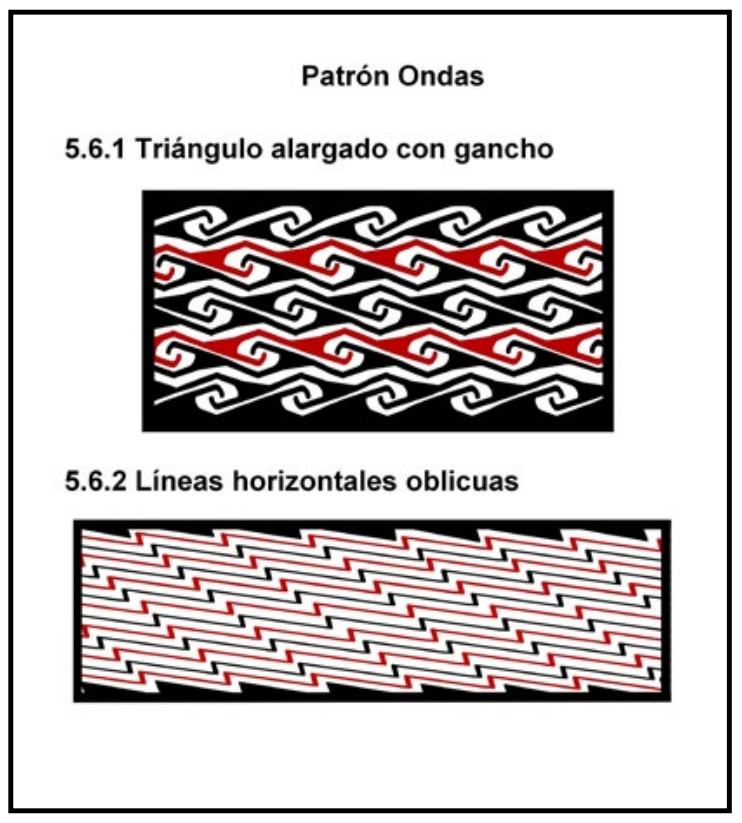

Figura 10. Patrón Ondas y sus variedades presentes en la muestra de estudio.

\section{Triángulo alargado con gancho}

Corresponde al patrón Ondas C5 definido por González (2013, p. 111). Se manifiesta por un diseño en campos discretos enmarcado por líneas negras. La muestra de estudio posee un ejemplar perteneciente a esta categoría.

\section{Lineas horizontales oblicuas}

Corresponde al patrón Ondas F3 definido por González (2013, p. 119). Se manifiesta por un diseño en campos discretos enmarcado por líneas negras. La muestra de estudio posee dos ejemplares pertenecientes a esta categoría.

\section{Configuraciones mixtas que utilizan simetrías complejas}

Este diseño proveniente de Caldera contiene una variante de los motivos diaguita patrón Cadenas D1 y Líneas quebradas A1 (González, 2013, pp. 137,143). Si bien ambos diseños serían de origen preincaico, se encuentran separados por una franja horizontal de rectángulos oblicuos (Fernández Baca, 1971, p. 205, fig. 556), los cuales en este caso son de color rojo y están delimitados por líneas negras. Rematan la parte superior del diseño una franja vertical roja que llega hasta el labio, y en la parte inferior, una franja negra. Esta combinación es un caso único que se aprecia en una vasija de Caldera (Figura 11).

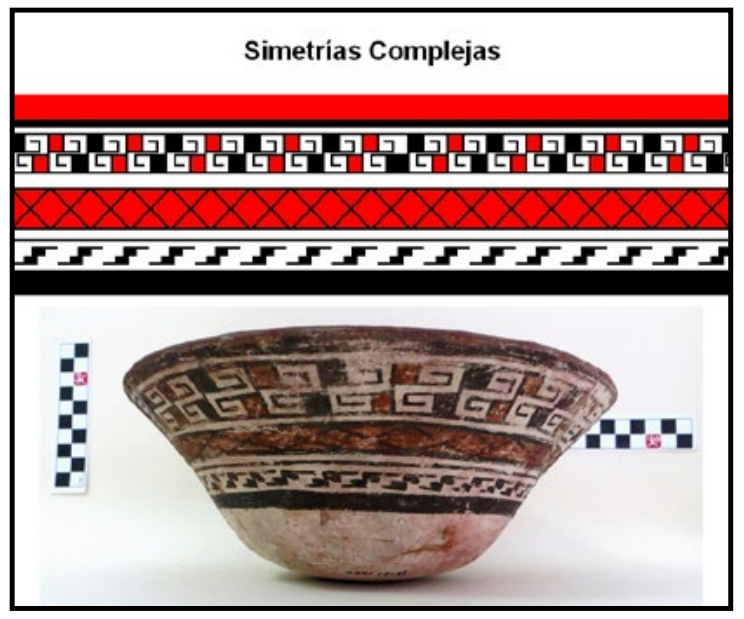

Figura 11. Arriba, diseño bidimensional que mezcla patrón Cadenas, Rombos en hilera y Líneas quebradas. Abajo, vista del puco que presenta dicho diseño.

\section{Configuraciones basadas en franjas de decoración de borde de vasijas}

Algunos pucos que no poseen diseños en su superficie exterior solo presentan como decoración una delgada franja en el borde, que se despliega apegada al labio. Esta decoración puede presentarse tanto en el borde interior como en el exterior de la vasija. En general sus diseños son de baja complejidad, con una repetición continua de su unidad mínima. La mayor parte corresponde a expresiones locales de Copiapó. Sus variantes detectadas en este estudio se aprecian en la Figura 12 y se describen a continuación. 


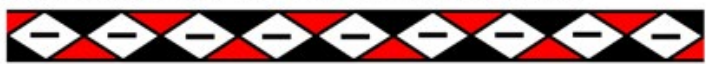

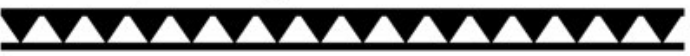

Figura 12. Franjas de borde y sus variedades presentes en la muestra de estudio.

\section{Franjas con cuadrados en desplazamiento}

Este patrón posee como unidad mínima un cuadrado de contorno negro que posee en su interior un pequeño rectángulo sólido que puede ser de color rojo o negro. En ciertos casos puede existir una línea negra horizontal que sigue el contorno del diseño debajo de él. Este patrón se manifiesta como un diseño continuo alrededor del borde de la vasija. La muestra de estudio posee dos ejemplares pertenecientes a esta categoría.

\section{Franjas con cuadrados y lineas verticales}

Este patrón posee como unidad mínima un cuadrado de color sólido que se repite en traslación a lo largo de una banda continua. Entre ellos se encuentra una serie de líneas verticales paralelas que los separan. Es similar al patrón unidireccional Rectángulos en rotación, de González (2013, p. 215), el cual tiene una escasa representación en la zona diaguita, caracterizado por solo un ejemplar del valle del Elqui. En la muestra de estudio se aprecia solo en dos ejemplares de Caldera.

\section{Franja de lineas horizontales paralelas}

Es un patrón unidireccional que se caracteriza por la presencia de líneas rojas horizontales paralelas enmarcadas en su parte superior e inferior por líneas negras. Se manifiesta como una banda continua alrededor del labio de la vasija. La muestra de estudio posee un ejemplar perteneciente a esta categoría.

\section{Franja con triángulos en hilera}

Este patrón se compone de triángulos invertidos de color negro que se trasladan horizontalmente y están delimitados en su parte inferior por una línea horizontal negra. Es un diseño que cae dentro de la categoría de "motivos dentados", según Fernández Baca (1971). Se manifiesta como un diseño continuo por la superficie interior de las vasijas, consistiendo en una línea delgada apegada al labio. La muestra de estudio posee un ejemplar perteneciente a esta categoría.

\section{Franjas con rombos y/o clepsidras en hilera}

Es una variante del patrón cuzqueño Rombos en hileras A definido por González (2013, p. 219), siguiendo a Fernandez Baca (1971). Los rombos son blancos y presentan una línea horizontal en su interior. Entre ellos, se forman "clepsidras" con una mitad de color rojo y la otra de color negro, las cuales alternan colores con sus vecinos. Este patrón se manifiesta como un diseño continuo por la superficie interior de las vasijas, consistiendo en una línea delgada apegada al labio. La muestra de estudio posee un ejemplar perteneciente a esta categoría. 


\section{Configuraciones basadas en diseños finitos}

Algunos de los pucos presentan diseños finitos dispuestos en un patrón de cuatripartición simétrica, principalmente por la superficie interior de la vasija. Tales diseños pueden consistir en triángulos, franjas rectangulares verticales. A su vez, tanto los triángulos como las franjas pueden incluir diseños zoomorfos de aves a partir de su forma inicial. González (2013, pp. 191, 270) describe que este patrón se da preferentemente en pucos acampanados, cuyas unidades mínimas se repiten por un principio de rotación en cuatro vueltas. Sus variantes detectadas en este estudio se aprecian en la Figura 13 y se describen a continuación.

\section{Triángulos}

Este motivo corresponde a triángulos que pueden en ciertos casos tener pestańas o apéndices en su perímetro, y además presentan en ciertos casos diseńos en su interior. Las variedades identificadas en la muestra se aprecian en la Tabla 7.

Tabla 7. Variantes Patrón 5.9.1

\begin{tabular}{|c|c|c|}
\hline Variante & $\begin{array}{c}\mathrm{N}^{\circ} \text { de } \\
\text { ejemplares }\end{array}$ & $\begin{array}{l}\text { Campos de } \\
\text { diseño }\end{array}$ \\
\hline $\begin{array}{l}\text { 5.9.1.1 } \\
\text { Patrón A1 Triángulo } \\
\text { negro con apéndices } \\
\text { lineales (González, 2013, } \\
\text { p. 272) }\end{array}$ & 3 & $\begin{array}{c}\text { Unidades discretas } \\
\text { por el interior de } \\
\text { la vasija }\end{array}$ \\
\hline $\begin{array}{l}\text { 5.9.1.2 } \\
\text { Patrón B1 Triángulo } \\
\text { escalonado (González, } \\
\text { 2013, p. 273) }\end{array}$ & 1 & $\begin{array}{c}\text { Unidades discretas } \\
\text { por el interior de } \\
\text { la vasija }\end{array}$ \\
\hline 5.9.1.3 & 1 & $\begin{array}{c}\text { Unidades discretas } \\
\text { por el interior de } \\
\text { la vasija }\end{array}$ \\
\hline 5.9.1.4 & 1 & $\begin{array}{c}\text { Unidades discretas } \\
\text { por el exterior de } \\
\text { la vasija }\end{array}$ \\
\hline $\begin{array}{l}\text { 5.9.1.5 } \\
\text { Patrón Triángulos } \\
\text { Reticulados Opuestos } \\
\text { D con una voluta en la } \\
\text { punta (González, 2013, } \\
318 \text { ) }\end{array}$ & 1 & $\begin{array}{c}\text { Unidades discretas } \\
\text { por el interior de } \\
\text { la vasija }\end{array}$ \\
\hline 5.9.1.6 & 1 & $\begin{array}{c}\text { Unidades discretas } \\
\text { por el interior de } \\
\text { la vasija }\end{array}$ \\
\hline
\end{tabular}

\section{Franjas rectangulares verticales en cuatripartición}

Además de la presencia de triángulos en cuatripartición, es posible apreciar en la muestra franjas o rectángulos verticales en una disposición similar. Sus variantes en la muestra de estudio se describen en la Tabla 8.

Tabla 8. Variantes Patrón 5.9.2

\begin{tabular}{|l|c|c|}
\hline \multicolumn{1}{|c|}{ Variante } & $\begin{array}{c}\mathbf{N}^{\circ} \text { de } \\
\text { ejemplares }\end{array}$ & $\begin{array}{c}\text { Campos de } \\
\text { diseńo }\end{array}$ \\
\hline $\begin{array}{l}\text { P.9.2.1 } \\
\text { (Gonzón Cadenas C 4-2 2013, 134) }\end{array}$ & 1 & $\begin{array}{c}\text { Unidades } \\
\text { discretas por el } \\
\text { interior de la } \\
\text { vasija }\end{array}$ \\
\hline 5.9 .2 .2 & 1 & $\begin{array}{c}\text { Unidades } \\
\text { discretas por el } \\
\text { interior de la } \\
\text { vasija }\end{array}$ \\
\hline 5.9 .2 .3 & 2 & $\begin{array}{c}\text { Unidades } \\
\text { discretas por el } \\
\text { exterior de la } \\
\text { vasija }\end{array}$ \\
\hline $\begin{array}{l}\text { Similitud al patrón } \\
\text { cuzqueńo clepsidras }\end{array}$ & 1 & $\begin{array}{c}\text { Unidades } \\
\text { discretas por el } \\
\text { interior de la } \\
\text { vasija }\end{array}$ \\
\hline 5.9 .2 .5 & 1 & $\begin{array}{c}\text { Unidades } \\
\text { discretas por el } \\
\text { interior de la } \\
\text { vasija }\end{array}$ \\
\hline 5.9 .2 .6 & 1 & $\begin{array}{c}\text { Unidades } \\
\text { discretas por el } \\
\text { interior de la } \\
\text { vasija }\end{array}$ \\
\hline
\end{tabular}

\section{Motivos de aves}

Estos motivos corresponden a un triángulo o franja rectangular vertical de donde se desprenden una o dos líneas que terminan en un círculo con apéndices representando la cabeza de un ave. La cabeza de ave posee un punto central a modo de ojo, un cuello lineal largo y dos líneas paralelas que representan su pico. Estos motivos han sido asociados generalmente a una influencia del estilo La Paya o Santa María (Calderari, 1991; Cantarutti, 2002; González, 1995, 2013), si bien también han sido identificados en la cerámica Inca Cuzco y en Caquiaviri en 


\section{Diseños Finitos}

\subsubsection{Triángulos}
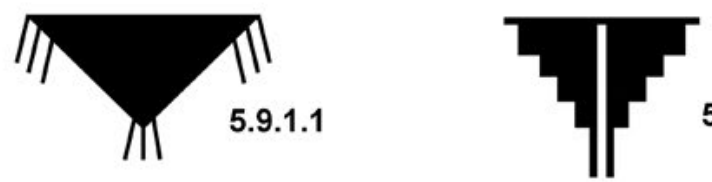

5.9 .1 .2
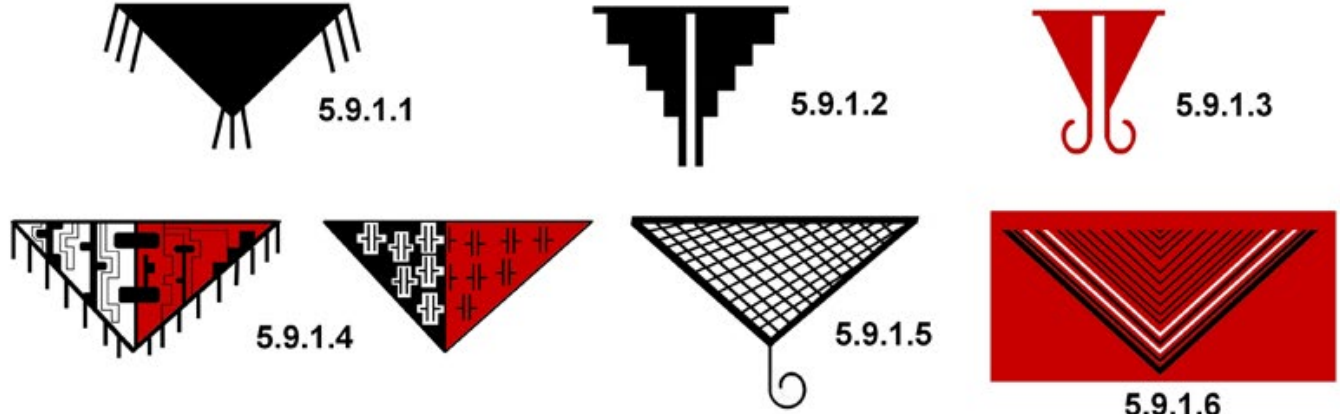

5.9.2 Franjas rectangulares verticales en cuatripartición
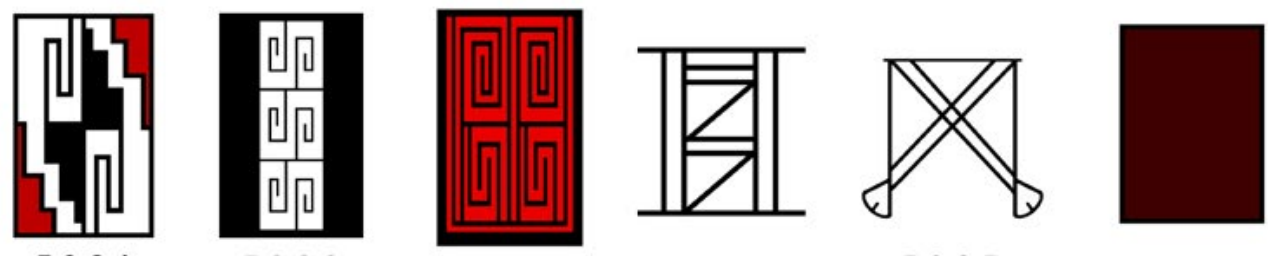

5.9.2.1

5.9.2.2

5.9.2.4

5.9.2.5

5.9 .2 .6
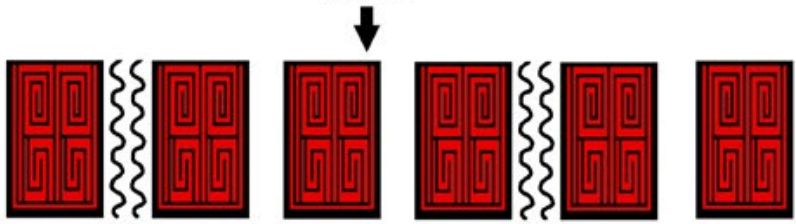

5.9.3 Motivos de aves

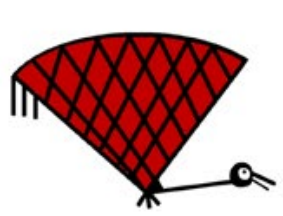

5.9.3.1

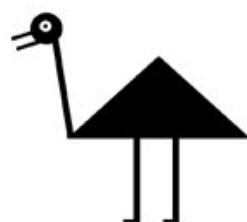

5.9 .3 .2

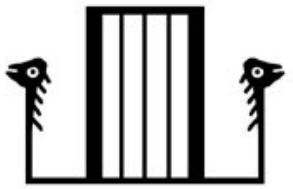

5.9 .3 .3

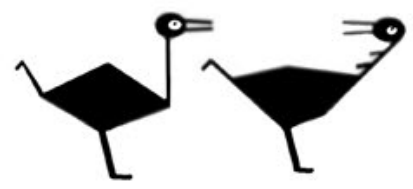

5.9.3.4

Figura 13. Diseños finitos y sus variedades presentes en la muestra de estudio. 
la zona del Titicaca (Fernández Baca, 1971; Pärssinen, 2015). Las variantes en la muestra de estudio se aprecian en la Tabla 9.

Tabla 9. Variantes Patrón 5.9.3

\begin{tabular}{|l|c|c|}
\hline \multicolumn{1}{|c|}{ Variante } & \multicolumn{1}{|c|}{$\begin{array}{c}\mathbf{N}^{\circ} \text { de } \\
\text { ejemplares }\end{array}$} & \multicolumn{1}{|c|}{ Campos de diseńo } \\
\hline $\begin{array}{l}\text { 5.9.3.1 } \\
\text { Patrón Cuatro Aves } \\
\text { de Cuerpo Reticulado } \\
\text { Oblicuo en Rotación } \\
\text { (González, 2013, 314) }\end{array}$ & 1 & $\begin{array}{c}\text { Unidades discretas por } \\
\text { el interior de la vasija }\end{array}$ \\
\hline 5.9.3.2 & 1 & $\begin{array}{c}\text { Unidades discretas por } \\
\text { el interior de la vasija }\end{array}$ \\
\hline 5.9 .3 .3 & 1 & $\begin{array}{c}\text { Unidades discretas por } \\
\text { el interior de la vasija }\end{array}$ \\
\hline 5.9 .3 .4 & 1 & $\begin{array}{c}\text { Unidades discretas por } \\
\text { el exterior de la vasija }\end{array}$ \\
\hline
\end{tabular}

\section{Otras configuraciones}

Corresponden a categorías de baja representación que no calzan en lo previamente descrito. Sus variantes detectadas en este estudio se aprecian en la Figura 14 y se describen a continuación.

\section{Ajedrezado con rectángulos verticales reticulados}

Corresponde al Patrón Ajedrezado B 5-2 definido por González (2013, p. 180). Se manifiesta de modo continuo por la superficie externa de la vasija. En la muestra de estudio hay un ejemplar de esta variante.

\section{Serpiente bicéfala}

Este patrón corresponde a una forma de $U$ rectangular, la cual en su interior presenta un diseño de puntos rojos y negros. Siguiendo el contorno de la figura, hay una línea central que termina en cada extremo en un rombo con un círculo central y un punto dentro de él. Posee cierta semejanza con el motivo Belén - Santa María del Noroeste Argentino, conocido como serpiente bicéfala (Castillo, 1998; Marchegiani et al., 2009; Tarragó, 2000). Este patrón se presenta por la superficie exterior de la vasija como un par en oposición. En la muestra de estudio hay un ejemplar de esta variante.

\section{Rostro Zoomorfo}

Corresponde al diseño central de las vasijas zoomorfas diaguita (Cornejo, 1989; González, 2013). Presenta diseño interior moteado, ojos formados por círculos concéntricos, nariz lineal vertical y boca rectangular horizontal perpendicular a la nariz. Se manifiesta en vasijas con tres campos decorativos, donde éste asume una posición central. En la muestra de estudio hay dos ejemplares de esta variante.

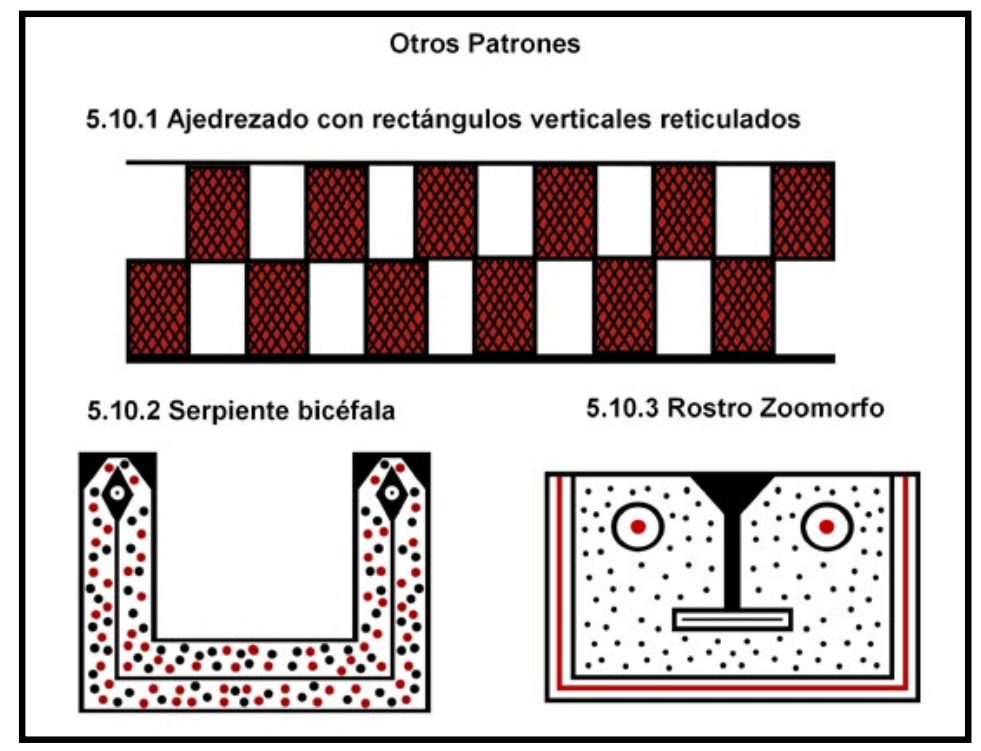

Figura 14. Otros patrones presentes en la muestra de estudio. 


\section{Análisis de la frecuencia de los patrones decorativos}

En cuanto a los patrones decorativos presentes en la muestra de estudio, hay una clara preferencia por el patrón Zigzag. Éste cuenta con un 37,5\% de representación en la superficie exterior de las vasijas, superando a cualquier otro por más del doble (gráfico A de la Figura 15). Le siguen en segundo lugar los patrones Rombos y Triángulos en Doble Reflexión Especular, Doble Zigzag y Greca Inca, con una frecuencia de entre el 10 y el $15 \%$ cada uno. Si analizamos en mayor profundidad las configuraciones específicas de tales patrones de diseño (Tabla 10), la categoría más abundante por la superficie exterior es el patrón Zigzag de triángulos rectángulos con volutas cuadradas, que generalmente se manifiesta a modo de campos discretos. Éste es seguido en frecuencia por el resto de los patrones Zigzag, el patrón de Rombos y Triángulos en Doble Reflexión Especular y la Greca Inca. Es relevante notar que la mayor parte de dichos patrones Zigzag, Doble Zigzag y Greca Inca corresponden a variaciones regionales de tales diseños decorativos. La excepción se da en el caso del patrón de Rombos y Triángulos en Doble Reflexión Especular que presenta un símil mucho mayor a sus homólogos del Elqui al sur, al igual que lo que acontece con la mayor parte de los otros patrones que tienen una proporción inferior al $5 \%$. La alta representación del patrón Zigzag también se ve en áreas como el valle de Illapel (González, 2004), indicando la alta popularidad de esta configuración de diseño de origen diaguita.

En cuanto a la superficie interior de las vasijas, un $54,6 \%$ de la muestra no posee decoración en esta área, demostrando la mayor relevancia del uso de la superficie exterior. El patrón predominante es la cuatripartición, representando el 57,7\% de los casos con decoración interior (gráfico B de la Figura 15). Este patrón se compone en su mayoría de cuatro motivos finitos, principalmente triángulos y franjas rectangulares verticales, en posición cercana al borde. Le siguen en frecuencia las franjas delgadas asociadas al borde-labio, mientras que el resto de los patrones tiene una muy baja representación. Las configuraciones específicas de Franjas delgadas de borde, Triángulos en cuatripartición, Franjas rectangulares y Representaciones de aves son las categorías mayoritarias presentes en la muestra.
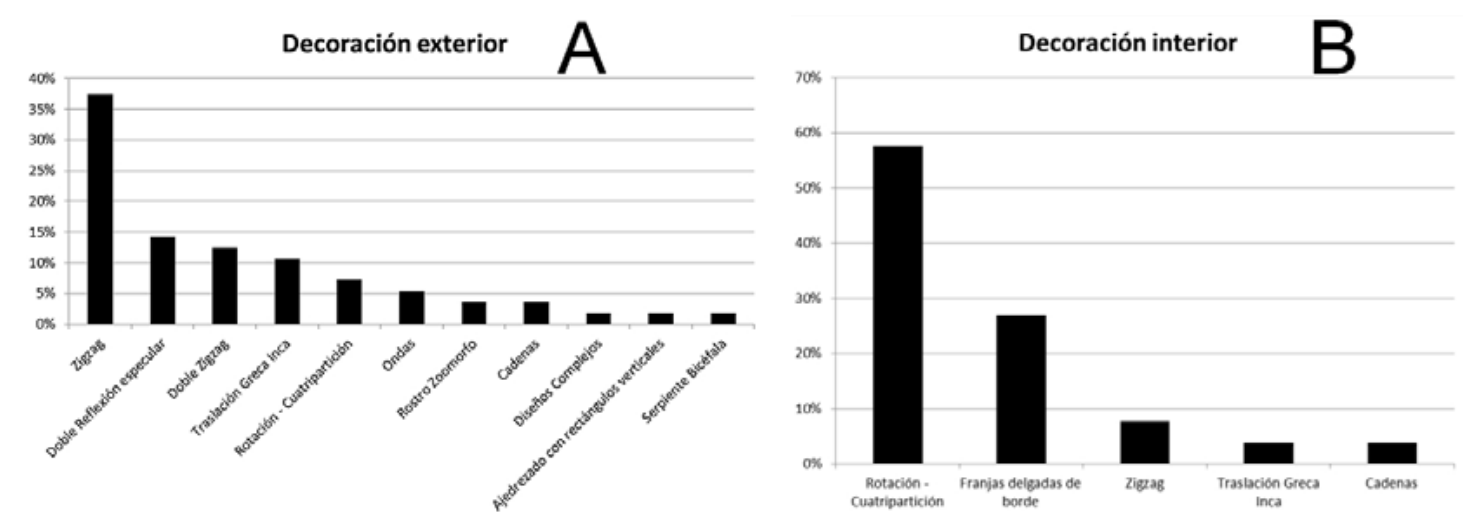

Figura 15. Configuraciones decorativas en la muestra de estudio. Gráfico A, decoración exterior. Gráfico B, decoración interior. 
Tabla 10. Representación porcentual de patrones en la muestra de estudio según su ubicación al exterior o interior de la vasija.

\begin{tabular}{|c|c|}
\hline \multicolumn{2}{|l|}{ Patrones en superficie exterior } \\
\hline $\begin{array}{l}\text { Zigzag de triángulos rectángulos con volutas } \\
\text { cuadradas }\end{array}$ & $14,3 \%$ \\
\hline $\begin{array}{l}\text { Zigzag de triángulos equiláteros y volutas } \\
\text { cuadradas }\end{array}$ & $12,5 \%$ \\
\hline Zigzag de triángulos isósceles opuestos & $10,7 \%$ \\
\hline $\begin{array}{l}\text { Doble Reflexión Especular cuatro triángulos } \\
\text { enfrentados por el vértice }\end{array}$ & $10,7 \%$ \\
\hline Greca Inca & $10,7 \%$ \\
\hline Doble Zigzag con volutas cuadradas & $8,9 \%$ \\
\hline Rostro Zoomorfo & $3,6 \%$ \\
\hline $\begin{array}{l}\text { Doble Reflexión Especular Rombos } \\
\text { escalerados }\end{array}$ & $3,6 \%$ \\
\hline Cadenas Escalerado con apéndice & $3,6 \%$ \\
\hline Franjas rectangulares verticales & $3,6 \%$ \\
\hline Ondas Líneas horizontales oblicuas & $3,6 \%$ \\
\hline Triángulos en cuatripartición & $1,8 \%$ \\
\hline $\begin{array}{l}\text { Doble Zigzag con triángulos isósceles y } \\
\text { círculos concéntricos }\end{array}$ & $1,8 \%$ \\
\hline Diseños Complejos & $1,8 \%$ \\
\hline Ajedrezado con rectángulos verticales & $1,8 \%$ \\
\hline Zoomorfo Aves & $1,8 \%$ \\
\hline Serpiente Bicéfala & $1,8 \%$ \\
\hline $\begin{array}{l}\text { Doble Zigzag con cuadrado negro y apéndice } \\
\text { vertical }\end{array}$ & $1,8 \%$ \\
\hline Ondas Triángulo alargado con gancho & $1,8 \%$ \\
\hline \multicolumn{2}{|l|}{ Patrones en superficie interior } \\
\hline Franjas delgadas de borde & $26,9 \%$ \\
\hline Triángulos en cuatripartición & $26,9 \%$ \\
\hline Franjas rectangulares verticales & $19,2 \%$ \\
\hline Zoomorfo Aves & $11,5 \%$ \\
\hline Zigzag de triángulos isósceles opuestos & $3,8 \%$ \\
\hline $\begin{array}{l}\text { Zigzag de triángulos rectángulos con volutas } \\
\text { cuadradas }\end{array}$ & $3,8 \%$ \\
\hline Cadenas Rectángulo unido a un gancho & $3,8 \%$ \\
\hline Greca Inca & $3,8 \%$ \\
\hline
\end{tabular}

\section{Diferencias decorativas entre la costa y el interior del valle de Copiapó}

La información de proveniencia de la muestra de estudio solo nos permite segregar con confianza entre costa y valle del río Copiapó, por lo cual se ha utilizado dicha división para analizar si existe alguna distribución diferencial entre tales sectores.

La data muestra que en la costa hay una preferencia por el patrón Greca Inca, mientras que el patrón Zigzag y sus variantes muestran una frecuencia mayor al interior del valle de Copiapó (Tabla 11). En general, la muestra costera presenta una menor diversidad de patrones de diseño, lo cual es también un efecto del reducido tamaño de la muestra. En aquellos casos en que hay presencia de decoración al interior de la vasija, vemos que los patrones de cuatripartición y la presencia de franjas continuas a lo largo del borde son comunes tanto en la costa como al interior del valle de Copiapó, aunque en la costa las franjas reflejan una proporción mayor dentro del conjunto.

En cuanto a la frecuencia de la configuración de campos de diseño (Tabla 12), los campos discretos son mucho más abundantes al interior del valle de Copiapó, en contraposición a lo que acontece con la presencia de campos continuos en la costa (Tabla 2). El análisis de Chi2 sobre las categorías campos discretos y continuos nos arroja una diferencia estadísticamente significativa al $95 \%$ entre costa y valle $(\mathrm{Chi} 2=3.862$. y probabilidad $\mathrm{p}$ $<.05)$. Si bien hay una importante superposición de diseños y patrones de simetría en ambas zonas, sus discrepancias sugieren la existencia de preferencias estilísticas que pudiesen tener correlato con la diversidad de unidades sociopolíticas que configuraron el territorio en tiempos incaicos, sobre todo considerando el hecho de que no hay evidencia de un sistema político homogéneo ni centralizado para la época. 
Tabla 11. Representación porcentual de categorías de patrones decorativos en la muestra de estudio, según localidad geográfica.

\begin{tabular}{|c|c|c|c|}
\hline \multicolumn{4}{|c|}{ Superficie Exterior } \\
\hline Patrón & Valle de Copiapó & Costa & Total \\
\hline Zigzag & $43,9 \%$ & $20,0 \%$ & $37,5 \%$ \\
\hline Rombos y Triángulos en Doble Reflexión Especular & $17,1 \%$ & $6,7 \%$ & $14,3 \%$ \\
\hline Doble Zigzag & $12,2 \%$ & $13,3 \%$ & $12,5 \%$ \\
\hline Greca Inca & $4,9 \%$ & $26,7 \%$ & $10,7 \%$ \\
\hline Rotación - Cuatripartición & $4,9 \%$ & $13,3 \%$ & $7,1 \%$ \\
\hline Ondas & $7,3 \%$ & $0 \%$ & $5,4 \%$ \\
\hline Rostro Zoomorfo & $0 \%$ & $13,3 \%$ & $3,6 \%$ \\
\hline Cadenas & $4,9 \%$ & $0,0 \%$ & $3,6 \%$ \\
\hline Diseños Complejos & $0,0 \%$ & $6,7 \%$ & $1,8 \%$ \\
\hline Ajedrezado con rectángulos verticales & $2,4 \%$ & $0,0 \%$ & $1,8 \%$ \\
\hline Serpiente Bicéfala & $2,4 \%$ & $0,0 \%$ & $1,8 \%$ \\
\hline \multicolumn{4}{|c|}{ Superficie Interior } \\
\hline Patrón & Valle de Copiapó & Costa & Total \\
\hline Configuración Rotación - Cuatripartición & $64,7 \%$ & $44,4 \%$ & $57,7 \%$ \\
\hline Franjas delgadas de borde & $17,6 \%$ & $44,4 \%$ & $26,9 \%$ \\
\hline Zigzag & $11,8 \%$ & $0,0 \%$ & $7,7 \%$ \\
\hline Greca Inca & $0 \%$ & $11,1 \%$ & $3,8 \%$ \\
\hline Cadenas & $5,9 \%$ & $0 \%$ & $3,8 \%$ \\
\hline
\end{tabular}

Tabla 12. Campos decorativos por localidad en la muestra de estudio.

\begin{tabular}{|l|c|c|c|}
\hline Localidad & Campos discretos & Campos continuos & Sin decoración exterior \\
\hline Costa & $33,33 \%$ & $53,33 \%$ & $13,33 \%$ \\
\hline Valle de Copiapó & $59,52 \%$ & $26,19 \%$ & $14,29 \%$ \\
\hline Total general & $\mathbf{5 2 , 6 3 \%}$ & $\mathbf{3 3 , 3 3 \%}$ & $\mathbf{1 4 , 0 4 \%}$ \\
\hline
\end{tabular}

\section{Discusión y conclusiones}

La incorporación local de elementos iconográficos diaguita-inca en los pucos del valle de Copiapó presenta una variabilidad estilística que en gran medida fue localmente definida. Esta alfarería "inca mixta" y de "fase Inca" (sensu Calderari y Williams, 1991) está representada por vasijas de tradición local como los pucos, que incorporaron en su mayoría configuraciones de diseño localmente adaptadas. De éstas, las más frecuentes son las variaciones de los patrones Diaguita-Inca del tipo Zigzag y Greca Inca ajedrezada. La expresión local de estas configuraciones decorativas también se manifiesta en la composición del diseño, en donde hay una clara predominancia de la configuración en campos discretos, de modo similar a lo presente en la cerámica Copiapó negro sobre rojo local. Sin embargo, es relevante notar que a pesar de lo anterior vemos también un quiebre con la tradición decorativa que venía desde las 
vasijas Ánimas II y Copiapó negro sobre rojo, en las cuales su diseño exterior es idéntico al interior (Garrido, 2007, 2011). En la muestra analizada hay una total discrepancia entre ambas superficies decoradas, estableciendo un nuevo modo de ejecutar la construcción visual de la vasija.

En general, la cerámica inca y sus prácticas de uso fueron un fuerte vehículo de transmisión ideológica por parte del imperio (Bray, 2003; Matos, 1999; Morris, 1998; Uribe, 2004), por lo cual la incorporación de elementos decorativos foráneos a vasijas locales sugiere por una parte una apropiación simbólica estatal de prácticas culinarias y funerarias locales; mientras que por otra, expresa la agencia local durante el proceso de creación de los nuevos sujetos imperiales provinciales. Lo relevante en el caso de Copiapó es el proceso selectivo de apropiación de los patrones de diseño diaguita e inca. Esta variabilidad podría deberse en parte a la baja jerarquización política y alta diversidad social de jefaturas locales en Copiapó (Castillo, 1998; Hidalgo, 1972), lo cual podría ser reflejo de una administración imperial relativamente descentralizada, en donde no todas las comunidades de la región fueron integradas a la economía política inca ni al sistema de la mit’a (Garrido y Salazar, 2017). En la misma línea, los múltiples modos de reinterpretación e hibridación de los referentes estilísticos Copiapó, Diaguita y Cuzqueños sugiere un escenario fragmentado de negociaciones en la incorporación de estas poblaciones al imperio. A pesar de la falta de contextos claros y lo reducido de la muestra ha sido posible detectar una diferencia distribucional entre costa y valle, en donde la Greca Inca predomina en el primer lugar, mientras que el patrón Zigzag lo hace en el segundo. Este último patrón presenta además muchas variantes locales, dando cuenta general de la versatilidad en la adopción y reinterpretación ideológica de referentes foráneos en la cultura material del nuevo contexto político de la época.

A pesar de los importantes cambios alfareros producidos, cabe destacar que no hubo un reemplazo de las tradiciones cerámicas preexistentes, y es así como las vasijas Copiapó negro sobre rojo coexistieron junto a los nuevos estilos de influencia foránea. En contextos arqueológicos como Iglesia Colorada, por ejemplo, se presenta un escenario en donde en casi todas sus sepulturas es posible apreciar un conjunto de vasijas Copiapó negro sobre rojo, Inca local, Diaguita III y otras variedades locales (Castillo, 1998). Este ejemplo demuestra que no hay una necesaria exclusividad contextual para estas vasijas, sugiriendo que un mismo individuo o colectivo podría estar accediendo a bienes de diversa adscripción social y cultural, expresando tanto imposición como prestigio individual e identidad local. Esta situación es similar a lo que sucede con los metales durante el período Tardío en Copiapó, en donde por una parte son introducidas nuevas tipologías como el tumi y aleaciones metalúrgicas de bronce estañífero, mientras que por otra, tecnologías previas de bronce arsenical y artefactos como manoplas, cinceles y placas permanecen y coexisten en la misma época (Garrido y Li, 2017). La evidencia en el caso de los metales sugiere que podrían haber existido dos economías políticas paralelas: la del Inca y sus aliados, en contraste con aquella de los líderes locales tradicionales.

Comparando la situación del valle de Copiapó con otras zonas lejanas del imperio inca en época tardía, es relevante la observación de Sanhueza (2001) acerca de los aríbalos de Chile central, en cuanto a que mientras las formas más se alejan del estándar cuzqueño, la configuración decorativa es más local en su estilo. Del mismo modo, en los conjuntos de alfarería de sitios como Quinta Normal (Cantarutti y Mera, 2002; Correa et al., 2007) se demuestra una vez más la presencia de contextos que evidencian variación e imitación de formas cuzqueñas, pero con diseńos decorativos que recogen elementos tanto Diaguita como Aconcagua. Otro punto importante es que al igual que en Copiapó, configuraciones de diseño como el patrón Zigzag también se encuentran asociados a vasijas no restringidas en sitios Tardíos de Chile central (Correa et al., 2007), dando cuenta de la amplia dispersión de este patrón en dicha época.

En conclusión, la cerámica del período Tardío de influencia diaguita e inca en Copiapó no puede interpretarse directamente como un ejemplo de dominación imperial absoluta e incontestada. Fuera del rol propagandístico e ideológico de la cerámica con atributos incaicos, la evidencia también sugiere que la mantención y coexistencia de vasijas locales, vasijas mixtas y de formas incaicas puede indicar que las 
actividades de comensalidad y funebria hayan sido un espacio de contestación y pugna, expresando intereses e identidades en conflicto. Por ello es que el estudio de la cerámica Tardía requiere comprender el rol que tales bienes jugaron en prácticas concretas de recreación de relaciones de poder, prestigio, jerarquías y asimetrías sociales en el valle de Copiapó durante la época inca, evitando el correlacionar uno a uno entre estilos y poblaciones. El desafío siguiente es emprender un estudio detallado sobre categorías cerámicas de formas propiamente incaicas como aríbalos y escudillas planas, con el fin de determinar cuán 'local' es su variación, y así abordar en mayor profundidad el impacto que tuvo el incario sobre los referentes visuales y morfológicos de la alfarería en Copiapó. Aquí estamos frente a un escenario mixto que manifiesta un panorama de convivencia y tensión entre la gente local de Copiapó, los nuevos administradores diaguita y el Estado inca.

\section{Referencias citadas}

Ampuero, G. (1978). Cultura Diaguita. Santiago de Chile: Ministerio de Educación, Departamento de Extensión Cultural.

Berenguer, J. (2009). Chile bajo el imperio de los Inkas. Santiago de Chile: Museo Chileno de Arte Precolombino.

Bray, T. (2003). To dine splendidly: imperial pottery, commensal politics and the Inca State. En Bray, T. (Comp.). The archaeology and politics of food and feasting in early states and empires (pp.142-163). New York: Kluwer Academic/Plenum Press.

Bray, T. (2004). La Alfarería Imperial Inka: Una Comparación entre la Cerámica Estatal del Área de Cuzco y la Cerámica de las Provincias. Chungara. Revista de Antropologia Chilena, 36(2), 365-374.

Bray, T. (2009). The Role of Chicha in Inca State Expansion, a Distributional Study of Inca Aribalos. En Jennings, J. y Bowser, B. (Eds.). Drink, Power, and Society in the Andes (pp. 108-132). Gainesville: University Press of Florida.

Calderari, M. (1991). Estilos cerámicos incaicos de La Paya. En Actas del XI Congreso Nacional de Arqueología Chilena, vol. 2 (pp. 151-163). Santiago de Chile: Sociedad Chilena de Arqueología.
Calderari, M. y Williams, V. (1991). Re-evaluación de los estilos cerámicos Incaicos en el noroeste argentino. Comechingonia (número especial), 73-95.

Cantarutti, G. y Mera, R. (2001). Alfarería de la Fase Inca en el Valle de Limarí: Evidencias de Influencia Yavi o Chicha en Jarros Antropomorfos. En Actas del IV Congreso Nacional de Antropología Chilena (pp. 1383-1391). Santiago de Chile: Colegio de Antropólogos de Chile.

Cantarutti, G. y Mera, R. (2002). Alfarería del cementerio estación Matucana: ensayo de clasificación y relaciones con la cerámica del período Inca de Chile central y áreas vecinas. Revista Werkén, 3, 147-170.

Cantarutti, G. y Mera, R. (2004). Estadio fiscal de Ovalle: redescubrimiento de un sitio Diaguita-Inca en el valle del Limarí. Chungara. Revista de Antropología Chilena, 36(2), 833-845.

Castillo, G. (1998). Los períodos intermedio tardío y tardío: desde la cultura Copiapó al dominio Inca. En Niemeyer, H., Castillo, G. y Cervellino, M. Culturas prehistóricas de Copiapó (pp. 163-282). Copiapó: Museo Regional de Atacama, Copiapó.

Cornejo, L. (1989). El plato zoomorfo Diaguita: variabilidad y especificidad. Boletín del Museo Chileno de Arte Precolombino, 3, 47-80.

Cornejo, L. (2001). Los Inka y sus aliados Diaguita en el extremo austral del Tawantinsuyu. En Aldunate, C. y Cornejo, L. (Comps.). Tras la huella del Inka en Chile (pp. 74-89). Santiago de Chile: Museo Chileno de Arte Precolombino.

Cornely, F. (1956). La cultura Diaguita chilena y cultura de El Molle. Santiago de Chile: Editorial del Pacífico.

Correa, I., Bahamondes, F., Uribe, M. y Solervicens, C. (2007). Contextos alfareros de interacción social: lo local y lo foráneo en el cementerio Inca de Quinta Normal. Revista Chilena de Antropología, 19, 143-171.

D’Altroy, T. (2015). The Incas. Malden: John Wiley \& Sons.

Fernández Baca, J. (1971). Motivos de ornamentación de la cerámica Inca-Cuzco. Lima: Librería Studium editores.

Garrido, F. (2007). El camélido sagrado y el hombre de los valles: Una aproximación a la Cultura Copiapó y sus re- 
laciones a partir de la alfarería. Memoria para optar al título de Arqueólogo. Universidad de Chile, Facultad de Ciencias Sociales, Santiago.

Garrido, F. (2011). Identidades y cambio en la transición del período medio al intermedio tardío en el valle de Copiapó. En Páez, M. y De La Fuente, G. (Comps.). La cerámica arqueológica en la materialización de la sociedad: transformaciones, metáforas y reproducción social (pp. 2744). Oxford: South American Archaeology Series 14, British Archaeological Reports.

Garrido, F. (2014). Hacia una definición Tipológica de la Cerámica Punta Brava de la Cultura Copiapó. Boletín del Museo Regional de Atacama, 5, 19-35.

Garrido, F. (2016). Rethinking imperial infrastructure: a bottom-up perspective on the Inca Road. Journal of Anthropological Archaeology, 43, 94-109. http://www.sciencedirect.com/science/article/pii/ S0278416516300599

Garrido, F. y Li, T. (2017). A handheld XRF study of Late Horizon metal artifacts: implications for technological choices and political intervention in Copiapó, northern Chile. Archaeological and Anthropological Sciences, 9, 935942. http://link.springer.com/article/10.1007/s12520016-0315-2

Garrido, F. y Salazar, D. (2017). Imperial expansion and local agency: a case study of labor organization under Inca rule. American Anthropologist, 119(4), 631-644. https:// doi.org/10.1111/aman.12924

González, P. (1995). Diseños cerámicos Diaguita-Inca: estructura, simbolismo, color y relaciones culturales. Memoria para optar al título de Arqueóloga. Departamento de Antropología de la Universidad de Chile, Santiago de Chile.

González, P. (2000). Patrones decorativos de las culturas agroalfareras de la Provincia del Choapa y su relación con los desarrollos culturales de las áreas aledańas (norte chico y zona central). En Actas del XIV Congreso Nacional de Arqueología Chilena, tomo II (pp. 191-221). Copiapó: Museo Regional de Atacama.

González, P. (2004). Patrones decorativos y espacio: el arte visual diaguita y su distribución en la cuenca del río Illapel. Chungara. Revista de Antropología Chilena, 36 (suppl.), 767-781.
González, P. (2013). Arte y cultura diaguita chilena: simetría, simbolismo e identidad. Serie Monográfica de la Sociedad Chilena de Arqueología 2. Santiago de Chile: Ucayali editores.

Hidalgo, J. (1972). Culturas Protohistóricas del Norte de Chile. Santiago: Universidad de Chile.

Iribarren, J. (1958). Arqueología del Valle de Copiapó. Revista Universitaria, 43 (22), 167-195.

Marchegiani, M., Palamarczuk, V. y Reynoso, A. (2009). Las urnas negro sobre rojo tardías de Yocavil (Noroeste Argentino): reflexiones en torno al estilo. Boletin del $M u-$ seo Chileno de Arte Precolombino, 14(1), 69-98.

Matos, R. (1999). La cerámica Inca. En Los Incas. Arte y símbolos (pp. 109-165). Lima: Banco de Crédito del Perú.

Meyers, A. (1975). Algunos problemas en la clasificación del estilo incaico. Pumapunku, 8, 7-25.

Morris, C. (1998). Inca strategies of incorporation and governance. En Schwartz, D. (Comp.). Archaic states (pp. 293-309). Santa Fe: School of American Research Press.

Niemeyer, H. (1986). La ocupación Incaica en la Cuenca Alta del Río Copiapó. Revista Comechingonia (número especial), 165-294.

Niemeyer, H., Castillo, G. y Cervellino, M. (1993). Estrategia del dominio Inca en el valle de Copiapó. En Actas del XII Congreso Nacional de Arqueología Chilena (pp. 333- 371). Temuco: Sociedad Chilena de Arqueología.

Pärssinen, M. (2015). Collasuyu of the Inka state. En Shimada, I. (Comp.). The Inka empire: A multidisciplinary approach (pp. 265-285). Texas: University of Texas Press.

Rice, P. (1987). Pottery analysis. A source book. Chicago: University of Chicago Press.

Sanhueza, L. (2001). El aríbalo Inka en Chile central. Revista Werken, 2, 47-69.

Tarragó, M. (2000). Chacras y pukaras. Desarrollos sociales tardíos. En Tarragó, M. (Comp.). Pueblos originarios y la conquista: nueva historia argentina (pp. 257-300). Buenos Aires: Editorial Sudamericana. 
Troncoso, A., Pavlovic, D. (2013). Historia, saberes y prácticas: Un ensayo sobre el desarrollo de las comunidades alfareras del norte semiárido chileno. Revista Chilena de Antropología, 27, 101-140.

Uribe, M. (2004). El Inka y el poder como problemas de la arqueología del Norte Grande de Chile. Chungara. Revista de Antropología Chilena, 36(2), 313-324.
Uribe, M. y Sánchez, R. (2016). Los Incas en Chile. Aportes de la arqueología chilena a la historia del Tawantinsuyu. En Falabella, F., Uribe, M., Sanhueza, L., Aldunate, C. e Hidalgo, J. (Comps.). Prehistoria en Chile. Desde sus primeros habitantes hasta los Incas (pp. 529-572). Santiago de Chile: Universitaria. 